\title{
Ordenanzas para corregidores de indios del Virrey Don Francisco de Toledo
}

\author{
PUBLICA POR VEZ PRIMERA RUBEN VARGAS UGARTE.
}

D. Francisco de Toledo ha recibido el sobrenombre de El Legislador $y$, en verdad, que lo merece, pues en esta parte su obra ha sido elogiada" aun por aquellos que le son adversos. De él como decía el Virrey Marqués de Montesclaros, todos cuantos le sucedieron fueron discípulos y de haberse atenido a las disposiciones por él tomadas no se trabrían producido tantas quiebras en la administración virreinal.

Sus Ordenanzas son bien conocidas. Ya Lorente en el tomo primero de las Relaciones de los Virreyes, publicado en 1867, dió a concer algunas de ellas. Más tarde, Roberto Levillier, les dedicó un tomo íntegro, el octavo en su Colección de Gobernantes del Perú, Madrid, 1952. En el tomo V de la Revista del Archivo Nacional del Perú se publicaron las Ordenanzas de Aguas, dadas en 1577 y acá o allá se han reproducido algunas de ellas.

Las que ahora publicamos por primera vez fueron dadas en Lima el 30 de Mayo de $1580 \mathrm{y}$, por tanto, son de las últimas que salieron de su nano. Figuran en la residencia que se tomó al Corregidor de la villa de Santa, Francisco de Mendieta, encomendada a Diego Galo de Ocampo, documento hallado por nosotros en el Archivo de Indias de Sevilla. La lectura de estas Ordenanzas nos confirma en el juicio que dimos sobre Toledo en el tomo primero de nuestra Historia del Perú, (Buenos Aires, 1949). Ellas son fruto de la experiencia y demuestran el cuidado que ponía Don Francisco en redactarlas y su espiritu de observación. Si algún defecto cabe señalar éste no es otro, sino la multiplicidad y prolijidad. La exhuberancia do las leyes es uno de los más graves obstáculos para su cumplimiento. Toledo debió darse cuenta de ello. Por otra parte, estamos ahora acostumbrados a una redacción más sintética de la ley y Toledo, por el contrario, peca de difuso muchas veces, en su empeño de que no se le escape pormenor alguno. Tal vez lo hizo para evitar las cábalas de la casuística y de la interpretación maligna a que se inclinaban los rábulas y tinterillos de esa época Y de todos los tiempos. 
Pero lo que más resalta en estas Ordenanzas es su empeño en proteger $y$ defender al indio contra las opresiones y vejaciones a que se veía sometido por la codicia y falta de humanidad de muchos. No eran solo los españoles los que caían en este delito, tanto o mas hacían los caciques, los primeros en extorsionar a sus súbditos y en aprovecharse de su trabajo. El que loa con desapasionamiento estas Ordenanzas no podrá menos de reconocer que Toledo fué un gran protector de la raza indígena y que está muy lejos de merecer el calificativo de tircno que le han aplicado algunos: indigenistas apasionados y desconocedores de lo verdadera historia.

Estas Ordenanzas servirán también para conocer muchos de los usos. y costumbres vigentes en aquel entonces y las prevenciones que fue preciso adoptar para sacar al indio de su pasividad $\theta$ inspirarle el sentido del progreso. Tal vez, de contar con tiempo bastante para ello, valdría la pena anotar algunas de estas Ordenanzas, así para aclarar su sentido, especialmente para quienes no tienen un conocimiento cabal de la época como para hacer resaltar el alcance e importancia de algunas disposiciones o bien deshacer. las aparentes contradicciones que pudieran descubrirse en un código de esta extensión. Dejamos esta tarea a otros más competentes y menos absorbidos por otra clase de trabajos.

Hemos conservado por regla general la ortografía del original $y$, sobre todo, las abreviaturas, fáciles de reconocer y descifrar. Casi al final hemos omitido la trascripción de la Carta acordada en la cual se concede jurisdicción a los Corregidores, pues no hace a nuestro intento y es sobradamente conocida. El lector podrá darse cuenta de que casi toda la parte postrera de estas Ordenanzas se refiere a los pleitos que se suscitaban entre los indios y el procedimiento que se había de seguir para sustanciarlos y dar la sentencia. Toledo sabía por experiencia lo tenaces que son los indios en esta parte y lo inclinados que son a promover litigios, en los cuales no dudan agotar sus pequeños ahorros. Puso cuidado en evitarlo y en facilitar la expedición de estos pleitos. Aun en los de mayor cuantía trató de ahorrarles a los indios los viajes largos y penosos a las Audiencias, pues aun en el mejor de los casos no podian hacerlo sin daño de sus intereses y de su propia familia.

Para el conocimiento de la Legislación Colonial, creemos que estas Ordenanzas constituirán un elemento valioso de información y por eso nos hemos decidido a publicarlas, aprovechando la gentil invitación del Director de esta revista, Dr. Javier Kiefer-Marchand, a quien sinceramente le domos las gracias. 
Interrogatorio por el cual se ha de hacer información secreta de lo obrado por Fco. de Mendieta. Corregidor de la villa de Santa y su partido cometida a Diego Galo de Ocampo. f. 24 a 26 v. Las preguntas son 44. Síguense de otra letra otras cinco preguntas en el f. 27.

Instrucción y Capítulos del Excmo. Sr. D. Fco. de Toledo Visorrey y jurisdicción de los corregidores f. 27 v.

f. 28 Tabla y sumario de lo contenido en esta ynstrucción y capitulos que S.E. manda que guarden los corregidores $y$ la jurisdicción que an de tener. Primeramente que bivan $\mathrm{y}$ den buen exemplo...

(Son 68 caps. term. f. 30 v.)

f. 31. Don Francisco de Toledo mayordomo de su magestad su visorrey governador y capitan general de estos Reynos e provincias del piru y tierra firme, pressidente del audiencia y chancilleria real que reside en la ciudad de los reyes en el piru \& Por cuanto de la vissita general q por mi persona y comisarios he hecho en estos reynos por mandado de S.M. $\alpha$ resultado proveer muchas cossas convenientes al descargo de su real conciencia y aver sido necessario dejar hordenanzas y estatutos en differentes géneros de negocios para que de aqui adelante rijan $\mathrm{Y}$ goviernen por ellas y cessen las exorvitancias que en alguna ha avido y los pleitos y diferencias que por falta deellas traen perdidos los españoles e naturales e para que los unos y los otros cobren el amor a la paz y temor a la justicia que como gente de pulicia son obligados a tener porque en casso que con las reales audiencias y con las justicias mayores y hordinarias S.M. tiene bastantemente proveido en los pueblos de españoles y la misma calidad de la tierra y la expiriencia de los negocios que suceden en la mina muestra claramente lo que se deve hordenar para que Dios N.S. Y S.M. sean servidos y nuestra conciencia como ministros suyos en quanto fuere posible se descargue porque siendo assi que estamos obligados a acudir y favorescer. la parte más flaca que es la de los naturales, pues sin ellos la república queda sin fuerza y sin las partes necessarias para su conversión, de manera que la justicia sea común a ellos y a los españoles, haziendo de todos una república y proveyéndola de manera que todos vivan justificadamente con ygualdad, que todos tengan entre si comercio y trato, porque si lo contrario se hiziese acostándonos a qualquiera de las partes con alguna violencia se da por averiguado que los unos y los otros ni governarian ni podrian sustentar como conviene para su aumento $\mathrm{y}$ perpetuidad, lo qual todas las ciudades $\mathrm{y}$ villas pobladas de españoles tienen menor necessidad de prebención, por la mucha justicia que en ella reside, pero los repartimientos y pueblos de yndios por estar en poblaciones distintas y apartadas como por aver sido la gente de esta tierra hasta aqui libres en hazerles tantas bejaciones y ser las mas de sus cossas tan menudas que, aviendose de benir a quejar ante la juticia y aunque sea la más cercana, son 
mayores las costas y travajo que en ello passan que el interese que se les podria seguir, aunque se les hiziese entera satisfacción de el daño que recivieron y ansimismo entre ellos ay pleitos de poca sustancia $\alpha$ unas repúblicas con otras como en particular a los mismos yndios y salen con tanta determinación a estos pleitos, que tienen en poco gastar su hazienda por conseguir qualquier cosa de poco interese $y$ asimismo como estan tan apartados de jueces de las ciudades y como es tan antigua la subjeción de sus caciques y principales que sobre ellos tienen, recive la gente menuda grandes daños e irremediables tiranias en sus personas, hijos y haziendas que por menudo tengo bastantemente averiguado sin osarse benir a quejar a quien les pueda hazer justicia sobre ello y juntamente con esto como es cossas hordinaria ynclinarse esta gente a los vicios e ydolatrias $y$ supersticiones de sus antecesores mayormente quando son flacos y nue vamente convertidos, como estos naturales tienen menos resistencias a las tentaciones buelvense a los sacrificios y cirimonias antiguas de la gentilidad haziendolos públicamente de que resulta gran daño y perjuicio para su conversión, mayormente teniendo como tienen consigo los viejos domatizadores, hechiceros que es eficacissimo estorvo della si no se pusiese recaudo en ello el qual no es bastante el que se da con los sacerdotes $y$ dotrina que les está puesta porque si ellos obiesen de entender en el castigo tambien repugnan a osar rescivir los yndios el sacramento de la con. fession con la libertad y entereza que se les predica, finalmente que considerando las sobredichas y otras muchas cossas que se an offrecido de que resultan notables inconvenientes de que los yndios y naturales no tengan justicia que mire provea $y$ castigue lo uno $y$ lo otro assi en lo que toca a estorbar los daños que resciven como a las partes se haga justicia sin costas que eran muy grandes y excessivas en embiar jueces comissarios ansi a hazer provanzas como a determinar los dhos pleitos sre todas las cosas que se ofrecian mayormente que se venian a seguir en grado de apelación por las mesmas personas de los caciques por lo cual hechavan derramas entre los naturales y lo tomavan por ocasión acaballos y disipallos y lo ue peor hera que no se podia averiguar verdad con todas las diligencias que se hazian y ansi mesmo que el miedo y castigo refrene las predicaciones de los viejos y apostasias y las muertes y sacrificios $y$ borracheras públicas y todo lo demás necessario porque no rescivan agravio e viban en pulicia me pareció cosa conveniente dividir los distritos de cada ciudad por partes y acomodarlos de manera que en cada uno haya una persona de cuya bondad y celo. se tenga satisfacción para que sea co. rregidor de los naturales en el distrito que le fuere señalado y tenga las facultades y preheminencias que por las hordenanzas que sobre esto se hizieren concedidas dandole salarios con que se puedan sustentan y limitóndole de manera que no sea con bexación ni molestia de los indios. y considerado el provecho que recive en todas estas cosas fuera de lo principal que es el mayor aparejo para su conversión es grande interese el que dello se sigue lo cual hasta agora no estava bien entendido ni la necesidad que de los dhos corregidores avia ni en lo que avian de entender hasta que por esta visita general se a visto $y$ de donde $y$ como se les 
avia de pagar el dho. salario con los quales ansimesmo se estatuyese un género de hermandad para seguir los delinquentes en todo el reyno tan bastante que con mediana diligencia que se tenga se pueda satisfacer el interese de la república quanto al castigo dellos porque en confianza de la aspereza de algunas provincias y de el poco recaudo que en esto se $\alpha$ puesto se an cometido muchos delitos que an quedado sin pugnición y hecho motines $y$ alteraciones $y$ no aviendo effeto se an huido por diferentes partes y salido deste reyno. finalmente por importar como importa al seguro paz y quietud de la tierra assi de españoles como de yndios y es averiguado que se avian de cometer mayores no proveyendose a necessidad tan bastante y ebidente por estar tan frequentado este género de delitos en este reyno por lo qual, allende de las provisiones que por $\mathrm{mi}$ les fueren dadas que an de guardiar y cumplir se an de governar y regir por las hordenanzas siguientes.

\section{Ynstrucción y hordenanzas que an de guardar los corregidores.}

Primeramte. que por quanto uno de los ynconvenientes mayores que se an hallado para el ympedimento de la conversación de los naturales deste Reyno es aver sido la vida y exemplo de los que con ellos tratan derechamente contrarias a nra predicación $y$ para que esto cesse os encargo que procureis vivir con la retitud y onestidad que de vra persona se confia porque cese el daño sobredho. con apercivimiento que será lo que con más diligencia se averiguará en la residencia que os fuere tomada para que cllende de ser castigado si lo contrario hiziese se terná quenta para no proveeros en semejantes cargos y oficios para acrecentaros o mejoraros haziendo lo que se os encarga y sois obligados.

Yten por quanto el administrar justicia $y$ tratar y contratar con los súbditos y comarcanos a ellos son negocios yncompatibles $y$ como tales prohibidos por todas las leyes $\mathrm{Y}$ premáticas reales, hordeno $\mathrm{Y}$ mando que los tales juezes de naturales no tengam tratos ni contratos el tiempo que lo fueren por si ni por interposita persona ni los hagan hazer ropa de ni en oira manera con sin paga ni sin ella por ynconveniente que de hazerse esto he hallado no solo no solo en su distrito pero en el de la ciudad donde cae so pena de privación de el salario aperciviéndole que será el segundo capítuio de que se ahrá averiguación en la residencia que se le tomare.

$Y$ por quanto es averiguado queen todas las provs. de estos reynos no es bastante la predicación evangélica que se a hecho después que se descubrieron $y$ ministros que S.M. a mandado poner para que entiendon en ella $y$ diligencias $y$ gastos que en ello se an hecho e ver rescivido los naturales o la mayor parte dellos los sacramentos de la Yglesia no no solamente en secreto pero aun públicamente hazen sus sacrificios e ydoiatrias $y$ enterramientos confissiones $Y$ hechizerias $y$ matrimonios $y$ fiestas genera les al uso antiguo de la gentilidad de que resulta notabledaño y perjuizio para su conversión y aun para la salud umana, hordeno y mando que de cada cossa destas tengais special cuidado de saver $y$ entender quien los haze y comete $\mathrm{y}$ advertireis que es negocio sustancial y mirar por los biejos 
y domatizadores y hechiceros ya referidos que son el ynstrumento y causa de todo mal y avisarles eys con prefaciones públicas para que se abstengan. y aparten de todo ello, certificándoles que se castigará con gran rigor como se a empezado hazer e que al que lo manifestare siendo negocio general y congregación pública para hazer lo suso dho. será reservado de tributo $Y$ se le darán otras franquicias y libertades y si saviéndose no lo manifestare, por la primera vez le serán dados cien azotes y será tresquilado públicamente y por la 2a. será condenado $\alpha$ muerte natural asi el que lo hiziere como el que lo encubriere en lo qual entedereis vos los dhos corregidores porque demás de ser deservicio de Dios tambien sereis gratificados por S.M. Y se os porná culpa por la negl gencia que en ello ho bieredes tenido y embiarme eis cada un año relación de lo que hobieredes hallado, tocante a esta materia o si hallais enmienda en los dhos ynds.

Yien porque de donde pende todo el daño de estos naturales es de las borracheras hordinarias que hazen y de aqui resultan las fuerzas y aman se ebamientos y sodomias e incestos, y allende de esto tengomaveriguado que ninguna borrachera se haze sin idolatrias, habiendose la chicha que es bre vaje de maiz y que en ella gran cantidad de supersticiones e todas las idolatrias e fiestas se hazen con las dhas borracheras y demás de lo que toca a la salvación destos ynds. que es a lo que principalmente, se deve adver tir, comogastando lo que cogen en lo susodho.quedan la mitad del año sin mantenimiento e comen muy poco en tanto que veven, resulta que como son tan sensuaies, como las enfermedades los toman debilitados por no comer cosa de sustancia, mueren sin ningun remedio de poderse curar, de manera que como cosa que conviene al ánima y al cuerpo conviene que se ponga remedio, por tanto hordeno y mando que ongais gran diligencia en estorbar las dhas borrocheras publicas, advirtiendo a los caciques e principales que si los ynds. las hizieren en lugares secretos se les porná tambien a ellos cuipa y procurareis persuadiendoles lo mucho que en ello les ba, que los dexen y coman mantenimientos de sustancia y si algun cacique fuere hallado borracho en borrachera en junta de indios o fuerra della por la primera vez será desterrado un año de su repartimiento el qual servirá en la ciudad en uno de los monasterios u ospitales que la justicia señalare y no le acudirán sus inds. con la tassa y alimentos que se le mandan dar $\mathrm{y}$ los dhos corre gidores pornan en su lugar quien gobierne dho tiempo y por la $2 \alpha$ vez que fuere hallado borracho será desterrado por otros 3 años por la forma suso dha y par la $3 \alpha$. como hombre incapaz inobed ente será privado perpetua mente de su cacicazgo y desterrado destos reynos, y si alguno de los atun runan se hallare borracho se le den 100 azotes por las calles de la ciudad o lugar donde fueren hallados por la forma acostumbrada y por la $2 a 200$ y tres quilado y sirva un año con una prisión al pie o al cuello en una obra pública o pia e por la 3a. se le d oble la pena de manera que sea escar miento $\mathrm{pr}$ ios demós leyéndoles y amonestándoles esta dha hordenanza porque por ella no se pretende quitarles su mantenimiento sino que beban a suscomidas e cenas como hombres concertados $y$ en sus casamientos cunque sean en compañia de los deudos lo puedan hazer con la dha moderación aperciviéndoles que como quiera que excedan seran castigados 
en la forma susodha.y las dhas penas executareis al doble si si los tales de estos borracheras hallaredes que se hazen de noche.

Y por quanto estos ynds. tuvieron por regla muy celebrada entre elios de adorar a los muertos de quien por linea recta procedian ignorando la primera causa de su creación como lo hicieron en todas las demás cosas de sus opiniones y ansi an tenido sepulturas en los campos distintas y aparta das de los pueblos y en otras partes dentro dellos y en otras en sus mismas casas ,porque en esto tubieron diferentes costumbres y para evitar el dho.

hordenco y mando que cada corregidor en su distrito aga $q$ todas las sepul turas de tierras se vusquen $y$ hagan hazer un hoyo grande donde se pongan rebueltos iodos los huesos de los diftos. que murieron en su gentitilidady tengan especial cuidado de aqui adelante de tener la ynteligencia que fuere posible para saver si alguno de los que fueron baptizados entierran fuera de las yglesias ayudando al sacerdote $y$ el juez el uno al otro como en cosa que es tan im ortante y tengan grande recaudo en las puertas de los templos porque los hurtan $y$ sacan de las sepulturas de noche quando son caciques e principales para el efecto susodho.e matan algunas mujeres $Y$ niños diziendo que los ban a servir $\alpha$ la otra vida e para a veriguación desto quando aigun cacique o su mujer miriere an de mirar luego el padrón dé los ynds e yndias que a de quedar en la caxa y archivo público de cada repartimiento para saber si falta alguno de sus parientes o criados asi barones como hembras de manera que si faltare alguno no puedan dezir que murió después de muerto el cacique y den quenta de los que faltan sobre lo qual se les encarga la conciencia a los dhos corregidores y con ellos se descarga la de S.M. y mia en su real nombre.

$Y$ por quanto los dhos naturales tambien adoran assi un género de aves $y$ animales e para el dho efecto los pintan y labran en los mates que hazen para vever de palo y de piata $y$ en las puertas de sus casas y los texen en los frontales $y$ doseles de los altares y los pintan en las paredes de las yglesias ,hordeno y mando que los que hallare dellos haga raer $y$ quitar de las puertas donde estubieren y prohivireis que tampoco los texan en la ropa que bisten, puniendo tambien sobre esto especial cuidado como cosa que toca a su ánima y descargo de la conciencia de S.M.

Por quanto es negocio muy sus ancial que los dhos corregidores den autoridad a la dotrina $y$ predicación que los sacerdotes hazen los domingos $y$ fiestas $y$ que los ynds. y naturales entiendan que los seglares y eclasiásticos en esto tienen toda conformidad hordeno y mando que en el pueblo donde los dhos corregidores se hallaren el domingo o fiesta de guardar a sistan con el sacerdote a la dha predicación mandando ansimesmo que los españoles qu alli hoviere esten al dho sermón $y$ predicación $y$ que no anden haziendo otros exercicios donde los yndios los puedan ber teniendo los dhos corregidores gran respeto a los dhos sacerdotes y acatándolos con mucha reverencia y si sobre algunas cosas confiriesen que no sea en presen cia de los dhos ynds. porque de esto resultan grandes daños que estan vistos so pena que se les hará gran cargo dello en la residencia y serán castigados conforme al escándalo que dello dieren. 
Yten por quanto por los visitadores generales todos los ynds, de el Reyno estan reducidos a pueblos $y$ elegidos los sitios y lugares dellos con todo acuerdoy parecer con las conside aciones $y$ mandatos que por mis yns trucciones les fueren dadas hordeno y mando que los dhos pueblos no se muden a otra parte ni los dhos corregidores los dejen mudar antes entiendan en que la dha reducción se concluya y acave y los dhos pueblos lleven la traza que les está dada y los ynds. hagan sus casas las que no estubieren hechas conforme a la dha traza que los visitadores dexaron y las yglesias, cárceles y casas de cavildo $\mathrm{y}$ no consientan que buelvan $\mathrm{y}$ hagan casas en los pueblos de donde fueron mudados, visitando los dhos lugares $Y$ mandando derrocarlas casas si algunas quedaron hechas y al que se hallare q. haze de nuevo le sean dados 100 azotes públicamte. si fuere yndio común y si fuere cacique o principal será condenado en 30 ps. aplicados pa pri siones de cárcel e pa otras obras necessarias pa su pueblo y se derrue quen a su costa por manera que por ninguna via dexen ni an de dexar ras tro de las casas biejas donde antiguamente bivian los dhos ynds. so pena que si dentro del año que entrare a ser corregidor no lo obiere mandado hazer en la visita que desto S.E. mandare hazer seran serán condenados en la quarta parte de su salario y seran derrocados a su costa eceto las casas que se dará por memoria a cada corregidor que an de dexar con forme a lo hordenado por los visitadores a las partes adonde an de ir a hazer las sementeras que por estar lejos de sus pueblos se an de qudar alguna noche a las beneficiar aunque pa el domingo an de estar los quales beneficiaran en su pueblo pa oyr misa y ser doctrinados so pena de 50 azotes que los ha de hazer dar los alcaldes de inds. yno lo haziendo el dgo corregidor castigue a los tales alcaldes.

Yten por quanto pa hazer la dha mudanza dexaron en muchas partes sus tierras desamparadas y lo $q$ se haze y hordena $p a$ su provecho no es justo $q$ resulte en su daño $y$ disminución hordeno y mando que ninguna persona les pueda tomar ni entrarseles en las dhas tierras so color de dezir que las tienen desamparadas y $q$ los dhos corregidores se las hagan amojonar si algunas no quedaron amojonadas por los visitadores poniendo mojones altos $y$ debaxo de cada uno enterrado un vaso de barro y dentro de el envuelto en un pedazo de encerado un testimonio ante escrivano de cuyas son las dhas tierras, qué linderos tienen a un cavo y a otro y firmado el testimonio del nombre de el dho corregidor dexando un registro de todo el dho amojonamiento de tierras en las casas de cabildo de el dho pueblo en el mesmo libro en que a de sentar los pleitos $q$ se determinaren porque se halle recaudo bastante cada que los inds. Io ovieren menester poniendo pena de muerte al que los quitare o mandare quitar sin autoridad de la justiciay no consientan $q$ en lo suso dho recivan daño ni perjuicio y si fueren de condición que por estar lejos no las pudieren beneficiar ni menos tubieren necesidad dellas parasus pastos y aprovechamientos y les conviniere bender las, en tal caso se guarde la horden q yo dexo dada sobre esta razón q si fuere tierra de comunidad no se pueda bender sin mi expresa licencia o del visorrey o governador que por tiempo fuere $\mathrm{y}$ si fuere indio particular sea necesario licencia de la Rl. Aud. del distrito so pena que la benta sea 
en si ninguna y el que lo comprase pierda lo que asi hobiera dado por la dha tierra de manera que los dhos inds no recivan daño ni perjuicio en sus haziendas sino que se les guarden y conserven commo a los españoles.

$\mathrm{Y}$ porque lo principal $\mathrm{q}$ se a de pretender pa la quietud de estos naturales esatajar los pleitos entre ellos porque a sido $y$ es su total destrucción yo di a los vistadores un capítulo de instrucción entre los demas $\mathrm{pa}$ que los averiguasen $\mathrm{y}$ ante ellos se an tratado por mi mandato $\mathrm{y}$ hecho la satisfacción conveniente a las partes ,hordeno y mando que sre negocio determinado por los tales visitadores y los dhos corregidores no se entremetan a conocer a pedimento de parte ni de sucesión ni consientan $q$ los dhos inds. tornen a tratar dellos en alguna manera porque lo $q$ pendiere en grado de apelación de las resultas de la dha vista las audiencias lo deaerminaran por la horden q S.M. manda y lo demas ase de quedar como cosa definida y acavada y guarden los amojonamientos $q$ los dexaron hechos entre los términos de algunos pueblos o chácaras de manera $q$ los dhos inds. entiendan q sre aquello no se pueda más litigar sinembargo de qualquiera razón que alegue.

Y por quanto como aveis entendido de la visita general a resultado hacerse la numeración y redución de los inds. de cada repartimiento y avelios hordenado sus pueblos con traza $y$ forma $y$ hazer sus casas con tan excesivos travajos $y$ costa pretendiendo su conversión y pulicia $Y$ dejandoles hordenados sus cabildos $y$ la forma de justicia $y$ juridición que an de tener entre ellos como queda en la tasa de cada repartimienta $q$ mando $q$ tengan en la caxa archivo de su comunidad conforme a lo que les quedó tasado el tributo de lo q an de pagar e si en los princi ios obiese descuido en la conservación desta horden hasta $q$ los mesmos hayan entedido la grande utilidad $q$ se les sigue devivir en congrega ciones, lo trabajado abrá sido sin fruto especialmte q por huir de las obras públicas asi de las yglesias q quedan comenzadas como de casas de cavildo hospitales $y$ otras obras necesarias pa el efecto $q$ se pretende $e$ romper las chácaras de nuevo de necesidad se les ha de hazer de mal podrian acometer a salirse de los pueblos e irse a chácaras de españoles e a otros repartimientos donde no se tenga quenta con eilos,hordeno $y$ mando $q$ por cora hasta $q$ otra $\cos \alpha$ se provea ningun indio salga de su tierra ni del lugar donde fuere reducido pa irs $\alpha$ vivir con su casa y familia - dexando su natural a otras partes ni español los lleve en su compañia so pena de 100 ps. aplicados por tercias partes e si algun cacique le recoxe de otros tantos y $\mathrm{q}$ al dho indio le sean dados 100 azotes, siendo indio comun $\mathrm{y}$ que el corregr tenga especial cuidado de executar la dha pena.

$\mathrm{Y}$ por quanto dado caso $\mathrm{q}$ en las instrucciones generales $\mathrm{q}$ yo di a los visitadores les mande dividiesen las tierras entre los naturales de manera q cada uno conociese lo que era suyo y cesase quanto a esto las exorvitancias de los caciques principales, porque tengo averiguado $q$ algunos les lleban tributos de lo $q$ cogen dellas porq se las den en buenas partes y fertiles $y$ adonde les davan menos de lo $q$ avian menester $y$ su sustentación y la dha. división no se puede en los más lugares del Reyno. 
especialmte en las tierras frias porq siembran los pagos de papas de 7 en 7 años y los dividen un año antes pa que los labren $y$ beneficien $y$ generalmte. en los tiempos pasados nunca tubieron cosa propia directa y aparte de la comunidad y asi la dha división no se puede hazer sin mucha dificultad por aora hordeno y mando q.las chácaras $q$ ovieren dividido los visitadores se guarde lo q ovieren dexado proveido y hordenado sre ello $\mathrm{y}$ donde no lo ovieren proveido $\mathrm{y}$ oviere la dificultad sobre dha. el dho corregr se halle presente a la dha dicisiónen cada un año si pudiere porq la hagan con toda rectitud y a cada uno le quede la parte $y$ pudiere beneficiar conforme a la gente $\mathrm{y}$ familiang tuviere $\mathrm{y}$ he cha la dha reparti ción visite algunos dias después $p a q$ vea $y$ entienda quien oviere sido negligente en sembrar o beneficiar lo $q$ le cupo y le reprenda o le haga algun castigo moderado pa $q$ entienda $q$ se tiene quenta con ello en lo qual a de tener muy especial cuidado como negocio de mucha importancia en las visitas $q$ hiziere en cada pueblo $y$ q los inds no anden ociosos sino $q$ travajen en las dhas sementeras en particular yen las de comunidad y $q$ los $q$ fueren oficiales travajen en sus oficios so pena $q$ el descuido se le porná por cargo en la residencia $q$ se le tomare y será castigado con forme a la remisión $q$ tubiere.

$Y$ por quanto yo dexo hechas ias tasas de los tributos con que an de acudir los ynds de los repartimientos a los encomenderos y dada horden corno esto se haga con toda rectitud $\sin q$ recivan agravio $y$ bivan con to da libertad $y$ sin la sujeción y opresión $q$ tenian tomándoles sus caciques como les tomavan sus haciendas $y$ les defraudavan prevaleciendo más a unos $q$ a otros $y$ porque con todo esto como la costumbre es vieja me pareció poner algun remedio pa adelante, hordeno y mando que si algunos ynds. se alquilaren con españoles q ningun cacique ni principal resivan en su poder el jornal o salario $q$ se les deve sino $q \alpha$ ellos mismos se les pague so pena $q$ el que lo contrario hiziere será castigado al arbitrio de los dhos corregidores y $q$ ellos tengan cuidado de proveer $q$ se guarde $y$ cumpla lo hordenado en esta hordenanza porq es de muy gran sustancia pa los efectos y se an pretendido y pretenden $y$ mandarla an fijas en las casas de cabildo de cada pueblo y si algun español dende la pubiicación della alquilare algs. ynds. y hiziere la paga dellos al cacique o principal condenarle an los dhos corregidores en lo $q$ obiere pagado, apiicado pa algunas obras de el dho pueblo y al cacique o principal $q$ lo resviciere en otro tanto como oviere rescibido segun dho es,porq. dende aora yo les doy por condenados en la dha pena y estareis advertido $q$ yo tengo tasados los jornales $q$ se deven pagar a cada yndio en cada distrito $o$ provincia, de tener memoria de la tassacion y $q$ conforme a ella se les paguen sus servicios y trabajos.

$Y$ porq. es bien $q$ yo entienda los ynds. $q$ en vro distrito se ocupan por mi horden $y$ mande $y r$ a la labor de minas ,chácaras o heredades o guardas de ganados de sus encomenderos e otras personas $y$ hazer mita a la ciudades, luego como llegaredes a vro distrito en la primera visita $q$ hizieredes os informareis de los caciques y principales de esto y me lo embiareis con distinción de cada repartimiento $y$ a quier $y$ cómo sirven $y$ 
ren $y$ en qué efetos $y$ lo $q$ se les suele pagar o si sabeis dexo o a dexado de pagar sus jornales pa que visto por mi provea lo que más convenga.

I por quichto lo principal $q$ se a de pretender en lo $q$ toca a los naturales como cosas de más importancia es su conversación y q sean presto edificalos y enseñados en las cosar de nra sta fe católica y y en quitarles todos los inconvenientes $q$ fueren estorvo $p a$ ello pa lo qual conviene $q$ el sacerdote o reïgioso $q$ estubiere en la doctrina no tenga con ellos traio ni granjeria, tierras ni ganados, porq con más libertad y entereza pueáa hazer si oficio, ni cepos ni córceles ni haga castigos, porque allende de el riesgo $c_{1}$ en eato corren ellos nimmos, el amor y buen exemplo e corrección fraternal pues an de ser curas de sus ćnimas es con lo q más lo an de atraer a q consigan el beneficio de su salvación y lo demás está prohivido por los sacros cánones como por la santa synodo que se celebró en este reyno hordeno y mando a con todo secreto entendais cmo se haze la coctrina en los pueblos de vro distrito sin hazer información sre ello I si ay alguno de ios estorbos dhos los quitareis hoziendo guardar y currelir lo $q$ sre ello está estatuido porq. la comida y camaricos $q$ hasta a jui daban 103 ynds y en alguna manera heran ocasión de los dhos tratos yo proveo se le den de otra manera pa q cesen $y$ en lo demás si vieredes q. no convienen como se haze avisareis al perlado $p a q$ lo remedie, aviendo ne gligencia a la Rl. Aud. en cuyo distrito estubieredes, procurando siempre hazerlo con tanto respeto $q$ no entiendan los ynds $q$ entre vosotros $y$ los dhos reiigiosos ay diferencia sino toda conformidad.

Ifem aveis de inquirir secretamte si los eclesiésticos q estan en la dotrina de los ynds. de qualquier calidad $q$ sean les an tomado chácaras $y$ otras heredades o ganados o plata omotras cosas o les hazen daño en sus ganacios e me dareis dello noticia o al que governare o a la Rl. Aud. pa q hagan $q_{1}$ sus perlados lo remedien $y$ les buelvan aqueilo $q$ obieren llevado $y$ tomado $y$ paguen los daños $q$ les ovieren hecho.

$Y$ por quanto en este reyno a avido algun desorden cista aqui así en hazer los dhos religiosos muchos edificios $q$ demás de no ser necesarios por ir sin el fundamento $q$ conviene se an caido $y$ en llevar los salarios estando ausentes de los ynds. q esiavan a su cargo y lo $1^{\text {o }}$ está proveido por células reales conforme a las quales ordeno y mando $q$ no consintais ni deis lugar q no se haga ninguna casa ni monesterio de nuevo sin expresa licencia de S.M. o mia en su Real nombre conforme a las dhas RR.CC. Y en lo demás no consentireis $q$ los dhos naturales hagan edificios más de los $q$ quedan trazados sin $q$ con vra información preceda licencia mia o del $q$ subcediere en el dho cargo y $q$ se sepa $q$ el salario a los dhos religiosos se les quiten al ausencia $q$ huvieren hecho, pagándoles solo lo $q$ obieren servido, teniendo especial cuidado $q$ no esté el pueblo sin doctrina avisando al perlado o governador o a la RI. Aud. quando faltare porqse provea con bredad y proveereis y los dhos ynds. no hagan donaciones por ninguna causa de su hazienda a ningun géneromde espariol ni religioso porq las hechas por y hazer doy y pronuncio por ningunas y de ningun valor y affeto como por auto lo rengo proveido en la prov. de chucuito y por las razones 
en el conienidas y q an si mismo no puedan hazer ventas de cosas de comunidal ni de particulares sin preceder las licencias atrás dhas de mas de las culez mando que primero $q$ se den las dhas licencias pa vender tierras de Ynds. de cominidad sejunten en su cavildo los alcaldes y regidores y cen su perecer sre si conbiene venderse ybel dho corregidor embie el suyo. con las razones por donde conbiene venderse.

Yien porquanto en algunas provs. como en el Coliao usan los dhos ynds.. de ciertos bonetes $y$ pa que vengan ajustados con la cabeza dende $q$ nace el niño se la aprietan con ciertas bendas trayéndole de esta manera hasta $q$ se endureze en lo qual allende de desproporcionar la hechura del hombre y quere enmendar la naturaleza humana a muchos dellos hazen saltar los ojos o que dan enfermos o cortos de vista, allende q es costumbre hozer el primer bonete con mucha cantidad de ceremonias y supersticiones asi ennel hilar de la lana como en tejerle dado caso q en la prov. de chicuito en ciertas hordenanzas $q$ yo hize di horden y y puse penas, pa lo susotho. no se hiziese de a qui adelante tenedreis especial cuidado de ver y entonder si en vros distrito donde haya inds. naturales y mitimaes $q$ estan repatidos por todo el reyno se usan de los dhos bonetes $Y$ hracen la dha viciencir $Y$ castigareis a los padres $y$ parteras con todo rigor porque cese lo susodho. como negocio de importancia.

Yten por quanto de la visita general resulta aver gran necesidad de atajar los malos tratamientos $q$ los principales hazen a los ynds. comunes y derramas q les echan tomando por ocasión que ban a seguir pleitos q convienen a la república ocupando mucho servicio $a$ ello y de sacarles las hijas contra su voluntad y darles los maridos $q$ los dhos caciques quieren $y$ de otras exorvitancias en $q$ conviene poner remedio hordeno $y$ mando $\alpha$ los dhos corregidores $q$ tengan especial cuidado $q$ ningun cacique ni principal maltrate los dhos ynds. ni consientan $q$ en poca $\mathrm{ni}$ en mucha canticad se les echen derramas y $q$ libremte les dexen tomar sus mujeres $y$ estado de matrimonio $q$ los dhos inds. quisieren $y$ fuere su voluntad ni se les lleve mós tributo de lo q les cupiere de su tassa y q dexen casar a los dhos ynds suz hijas librmte. so pena $q$ si en esto o en las dhas derramas se entemetieren de aqui adelante sean privados del cacicazgo $y$ en los denas y en los demas ser castigados ásperamente y si el dho corregir fuere negligente en averiguar lo susodho $\mathrm{y}$ en castigarlos en la residencia $q_{1}$ s? 10 tomare sea privado perpetuamte del oficio como hordeno y mando $q$ lo sea hallándose contra él aver incurrido en lo suso dho lo qual les de a entender en la congregación $q$ de estas hordenanzas se declaren en cadx un año.

Yten por quanto conviene $q$ los caminos esten aderezados y poblados los tambos pa q los caminantes tengan toda comodidad y proveidos de manera $q$ no tengan ocasión de yr a los pueblos a maltratar a los ynds. hordeno $y$ mando $q$ los dhos corregers tengan especial cuidado de lo susodho $y \mathrm{q}$ esten proveidos de mantenimientos $y$ tengan en ellos su aranzal por donde los an de vender $y$ despues aya cavallos tan baratos $y$ carneros de la tierra $q$ a de ver en cada tambo y venta pa llevar las cargas y $q$ S.M. tiene proveido $q$ los ynds no se carguen en ninguna 
manera lo areis cumplir y executar so pena $q$ el que llevare cargado indios incurra en pena de 10 ps. y de la carga q llevare el dho yndio aplicada por tercias partes a la cómara de S.M. juez y denunciador $\mathrm{y}^{\prime}$ hareis guardar en el servico del dho tambo la horden gral q yo téngo dada quanto a esto de los tambos y servicio dellos so pena $q$ si en lo uno $o$ en lo otro fueredes negligente sereis condenado en 10 ps. aplicados por tercias partes en la residencia $q$ se os tomare $y$ donde no estubiere dada la dha hordenhareis guardar la q fuere costumbre y me dareis aviso con vro parescer para que yo mande dar la q convenga de manera $q$ los dhos tambos se sirvan con el menos trabajo $q$ a los ynds. fuere posible informa doos de ellos si quieren encargarse de los tener poblados y bastecidos pa q sirvan y no a españoles y en el parecer q me dieredes aveis de llevar atención a q yo pretendo q los sirvan los ynds más cercanos a el y no por la costumbre antigua como lo hordené a los visitadores y mandé $q$ hiziesen las reducciones $q$ pudiesen en los propios tambos.

Yten por quanto no conviene $q$ los ynds. tengan arcabucesni balles tas espadas ni cotas por el daño q a ellos mesmos les biene dello y por otrasjustas consideraciones hordeno $\mathrm{y}$ mando $q$ tengais especial cuidado de recoger todos los arcabuces, cotas $\mathrm{y}$ ballestas $q$ entre ellos oviere $Y$ avisarles $q$ no los tengan de aqui adelante so pena de 50 ps. y perdido el arcabuz ,cota o ballesta de las quales terneis quenta y razón pa em biarlas al fin de cada un año como se os manda en otras cosas al gover nador destos reynos pa q de alli el las aplique a la parte $q$ le pareciere q conviene en las partes donde se entiende $q$ los ynds. suelen hazer pól vora $\mathrm{y}$ hareis pregonar $\mathrm{y}$ mandareis $\mathrm{q}$ no lo hagan sin expreso mandado de la Aud. o del corregr del distrito donde estubieren so pena de muerte.

$Y$ porq de la asistencia de los negros y mulatos y zambaryos $q$ residen entre los ynds. resultan algunos daños asi los que los mesmos naturales reciven delios como por la facilidad de las mujeres y malas costumbres en $q$ les ponen hordeno. $y$ mando $q$ ningun cacique ni principal ni yndio pueda tener mulato ni negro esclavo ni los horros puedan residir en los dhos pue blos so pena q si estubieren dos dias les serán dados 200 azotes los quale mando q después de executada la pena los dhos corregidores embien presosos a su costa a las ciudordes más cerçanas ,remitidos a la justicia pa $q$ los hagan servir $y$ asienten a oficios y con Amos, conforme a la horden q sre ello dexo dada en las dhas ciudades de la qual tomaréis copia la qual mando al escrivano de cabildo dellas $q$ os la de autorizada.

$Y$ por quanto se tiene entendido $q$ los dhos naturales tienen ocultos muchos minerales de oro y de plata y azogue $q$ antes solian labrar con te mor $\mathrm{q}$ se los an de tomar y no darles parte dellos hordeno y mando $\mathrm{q}$ los dhos corregidhes tengan especial cuidado de inquirir lo suso dho y avisar les en sus congregaciones de las libertades q S.M. les da en las hordenan zas de minas $\mathrm{q}$ yo dexo hechas y publicadas por virtud de las quales pueden gozar de lo q descubrieren como españoles y hombres libres y $q$ si no las manifestaren $\mathrm{y}$ otros las hailaren no ternan parte en ellas $\mathrm{y} q \mathrm{q}$ si fueren las minas que asi descubrieren de calidad $q$ se puedan seguir y pagar los tributos de lo q dellas sesacaren sean reservados de salir de sus tierras 
pa otras ningunas lo qual todo les hareis cumplir y guardar por la horden $q$ yo lo dexo proveido $\sin q$ les mengue cosa alguna haziéndoles toda justi cia $y$ retitud en los dhos descubrtos. pa lo qual mando $q$ agais $y$ tomeis de las hordenanzas de minas que quedan en la $\mathrm{cd}$. de vro distrito lo q toca a las libertades y preeminencias $q$ se da en ellas $a$ los ynds. pa $q$ se lo ha gan leer $y$ declarar las dos veces en el año $q$ se manda en estas hordenan zas $q$ se les lea $y$ declare lo $q$ ellos les toca en su lengua natural.

$Y$ por quanto esta bien entendido $y$ de rescatar con los $Y^{n d s}$. en los dhos pueblos coca les biene daño porq como llevan el dho rescate al tpo de la cosecha y las gentes de poca consideración danles el maiz q cogen por ello $y$ quedanse sin la comida necesaria pa su sustentación dandola por una golosina de tan poco fruto ,hordeno $y$ mando $q$ no consintais $q$ en ningun pueblo de los $q$ tubieredes a vro cargo haya el dho rescate so pena $q$ si fuese indio o india el q lo llevare incurra en pena de 100 azotes los qual les les dareis luego que averiguaredes aver rescatado, en caso q sea natural o extranjero de dho pueblo y si alguna otra persona llevare a vender o tratar cosas necescrias pa los dhos ynds. mando $q$ no se las den al fia do sino de contado pa q ninguno compre más de lo $q$ pudiere pagar y si se lo fiare $q$ no lo pueda pedir por justicia ni compelelle a $q$ lo pague ni vos le compelais $\alpha$ ello hasta $q$ el quiera $y$ provereeis $q$ ninguno de los mercaderes españoles pueda estar en el dho pueblo más de 3 dias entre los dhos ynds. y esto por el tpo q se permitiera aver la dha coca.

$Y$ porq de aver muerto los ynds. el ganado bravo de sus terrenos $\mathrm{y}$ distritos sin la órden $q$ solian tener se a apocado ,haziendo chacos $y$ si en esto no se les pusiere estanco seria ocasión pa q todo se acava se hordeno $y$ mando $q$ los dhos ynds no puedan hazer de aqui adelante los dhos chacos ni matar en ellos el dho ganado bravo sin mi expresa lica o del visorrey o governador queesubcediere en el dho cargo so pena $q$ el cacique $q$ lo mandare sea desterrado del repartimiento por término y espacio de un año $y$ los dhos corregides de naturales no lo aran ni consentiran hazer so pena de ser privadosde oficio perpetuamte.

$Y$ porquanto yo tengo proveida la horden $q$ de aver en ir los ynds. a los asientos de minas a ganar sus jornales $y$ tributos la qual dexo en cargada a los corregides hagan gua dar y cumplir porq de aqui pende la conservación de estos reynos mando $q$ tengais especial cuidado $q$ los inds $\mathrm{q}$ de vro distrito estuvieren mandado $\mathrm{q}$ acudan a. la labor de $\mathrm{y}$ beneficio de las dhas minas cumplan en este particular lo $q$ está proveido ,castigando al $q$ hiziere lo contrario cumpliendo los mandamientos de los corregides $y$ alcaldes mayores de minas a quien lo tengo cometido $q$ os acusaren de la falta q obiere so pena de 100 ps. aplicados por tercias partes porq los dhos corregides no an de embiar comisarios a costa de los dhos ynds. a ninguna excurciónpor las bexaciones $y$ molestias $q$ se les hazen por ellos sino $q$ vos los dhos corregides lo aveis de hazer $y$ cumplir segun $y$ como por ellos os fuere requerido $y$ mandado $y$ tener cuenta si an cumplido cada repartimiento con lo $\mathrm{q}$ se le echó $\mathrm{y}$ si se an buelto algunos ynds. de los $q$ fueron sin averse mudado $Y$ trocado por la horden $q$ acostumbrais $Y$ castigarlos eis con todo rigor haziendo q. siempre el número este cumplido 
$\sin q$ haya falta atto.a $q$ los mismos ynds. conviene pa el asiento $Y$ perpe tuidad de todo el reyno $y$ ynformaros eis de ordinario si algunos ynds.de los q estan empadronados se an huido de los dhos pueblos a otros 0 a poder de algunos españoles y los hareis bolver,castigándolos por la horden $q$ mejor os pareciere pa lo qual os doy poder pa q. despacheis fuera de vros distritos vras cartas y mandamientos los quales mando se obedezcan $Y$ cumplan so las penas $q$ en ellos pusieredes.

Yten por quanto los ynds an de tener ganados $y$ algunos an de andar cerca de los dhos pueblos como de ovejas y puercos de algunos caballos de españoles $q$ se sueltan $y$ desmandan $y$ hazen daño en las chácaras hordeno y mando que en cada pueblo de vro distrito hagais $q$ se haga un corral de concejo con su puerta ydiputareis cada año un indio $q$ sea mese quero y guarda de losdhos. para que se encierre el ganadoq andubiere desmandado $y$ hareis $q$ otro hagan el trabajo del $q$ entendiera en lo suso dho. ,de las penas en $q$ incurrieren, pero si el ganado no fueren bueyes de labor ni el dho bastare a evitar el daño el dueño de la heredad do de se hallare el tal indio el ganado mayor le pueda matar y mate y llevar quien lo ayude hazer si fuere toro o toros bravos en $q$. el dho yndio pueda tener peligro e echarlo de la dha heredad $y$ porq los ynds. tienencostumbre de estarse cada año con sus mujeres e hijos en las guardas de sus chácaras $y$ heredades sin tener necesidad dello $y$ por esto dexan de asistir en los pueblos de su reduccióny de acudir a la dotrina y enseñanza $y$ otros apro vechamientos temporales aveis de dar órden $q$ se nombren algunos ynds.

mesegueros $q$ tenga la guarda y custodia de las dhas haziendas como dho es a los quales no aviendo penas de que les pagar su travajo se lo hareis pagar a costa de los dueños de las dhas haziendas porq. ellos no tengan necesidad de ir de ordinario a la guarda dellas.

Yten por quanto yo he mandado hazer nuevas tasas $\alpha$ todos los ynds. de vro distrito de lo $q$ an de ser obligados a dar e pagar a S.M. por los q. son de su repartimiento $y$ asus encomenderos $y$ lo $q$ ansimesmo an de dar de tasa a sus caciques moderando en esto el,exceso $q$ asta aqui $a$ avido mando $q$ el salario $q$ se saca $\propto$ los caciques se saque de la gruesa de la tasa y los ynds. lo hagan solamente de la cantidad de chácaras $q$ ban declaradas y las den los ynds de servicio $q$ por las tasas se permite $y$ dado órden como se haya de distribuir y repartir la dha tasa entre los ynds. y $q$ vos les declareis lo $q$ les cave pagar pa $q$ los dhos caciques ni sus principales no cobren más dellos aveis de tener particular cuidado de ver lo $q$ por las dhas nuevas tasas se ordena $y$ manda $\alpha$ vos $y$ a los dhos caciques, oficiales $y$ encomenderos $y$ otras personas $y$ de la guarda $y$ cum plimto. de todo lo en ellas ordenado y me aveis de embiar fe y testimonio al fin de cada un año como por las dhas nuevas tasas se os hordena y manda de lo que en ello hizeredes so pena de que si no cumplieredes lo $q$ por las dhas nuevas tasas se hordena en la residencia que se os tomare se os hará cargo dello y de mas y demás de $q$ pagareis el daño a las partes del juez os castigue conforme al descuido o negligencia $q$ enello tuvie redes $\mathrm{y}$ execute las penas $q$ por las dhas nuevas tasas os estan puestas. 
$\mathrm{Y}$ porque ansimesmo tengo mandadas dar hordenanzas pa ei buen govierno de los naturales en las quales se os hordenan muchas cosas $q$ aveis de hazer y cumplir y allende de lo hordenado en esa ynstrucción y de hazer executar lo q en las dhas hordenanzas se manda a los caciques $e$ inds. aveis de tener mucho cuidado de ver y leer las dhas hordenanzas y $q$ se publiquen 2 veces en el año en cada repartimiento de vro distrito $\mathrm{pa}$ q asi vos como dhos ynds. seáis lo q aveis de guardar y cumplir allende que aveis de tener un treslado dellas pa q. mejor las hagais cumplir y guardar y so las penas en ellas hordenadas y en el capítulo antes deste.

Y porque en las nuevas tasas se os hordena y manda q hagais lista y padrón de todos los ynds de vro distrito y me embieis razón dello en cada un año de lo qual an resultado algunos inconvenientes de la numeración q. an hecho los corregides. porq como no las an hecho con el cuidado y diligencia $y$ espacio $q$ convenia an hallado algunas partes menos ynds $q$ por la visita manifestaron lo cual no se entinde ser ansi en los ynds serranos sino al contrario por las informaciones y delo he mandado hazer y q los caciques y principales los ocultan y esconden $p a q$ se relaxen las tasas $q$ les tengo dadas y pa cobrar lo $\mathrm{q}$ avian de pagar los ynds $\mathrm{q}$ asi ocultan pa si y pa q. cargue sre los demás y no en el dho repartimiento y conviene proveer en lo uno $\mathrm{y}$ en lo otro de remedio,por tanto solamente aveis de hazer la dha lista y numeración en los repartimientos q por particular comi sión mia se os mandaren y por la horden $q$ entonces se os diere y porq vos tengais quenta con los ynds. $\mathrm{q}_{\mathrm{r}}$ ay y sepais mejor si ban en crecimiento o no hareis secretamente lista de los ynds tributarios q ay en cada repar timiento la qual aveis de hazer una vez en el tpo q durare vro oficio y embiar un treslado al Governador quedando otro en vro poder pa q sepais los ynds. q. ay y lo podais entregar al Corregr. q os subcediere y hareis averiguación secreta al pie de la numeración de los aprovechamientos, tratos y granjerias q tienen los ynds. de cada repartimto. dadno sre ello vro parecer.

Iten aveis de tener mucho cuidado de q los ynds q hubiere en vro distrito de otros repartimientos se recoxan a sus naturclezas y hazzelles $q$ paguen la tasa q son obligados por lo $\mathrm{q}$ les tengo dada e por la $\mathrm{q}$ el corregr de su distrito osembiare a pedir y poner en esto el mismo cuidado $y$ diligencia $q$ en hazer $q$ paguen tasa los ynds. $q$ son de vro distrito so pena $q$ si no lo hiziereis $y$ se quexaren de vos los dhos caciques e ynds. o sus corregides será a vra costa el daño q reciviere la tasa que dexaren de cobrar y el mismo cuidado terneis en $q$ se reçoxan los ynds. de los repartimientos de vro distrito $q$ andubieren fuera del.

Yten por quanto en las hordenanzas $q$ tengo ciadas pa el govo de los ynds. mando $q$ los ynds $q$ no fueren casados $q$ no paguen más de $1 \alpha$ $1 / 2$ de la tasa $q$ an de pagar los $q$ lo fueren $y$ esto trae consigo inconve venientes de q los ynds. pa no pagar tasa por entero no se casan sino q se estan amancebados y teniendo consideración a esto y por otras justas causas, por las nuevas tasas tengo proveido y mandado $q$ la tasa la paguen los ynds solteros como los casados, terneis cuidado de hazerlo cumplir $y$ 
guardar así sinembargo de lo proveido en las dhas ordenanzas y de $q$ io entiendan los ynds.

Yten por quanto estoy informado $q$ en algunos repartims los caciques an escondido y de algunos ynds. de tasa de $q$ conviene haze averiguar ción hordeno $y$ mando $q$ en las visitas $q$ hizieredes cada uno de vos los dhos coregides recivais en cada un año el padrón de los ynds de vro distrito $q$ hizieron los visitadores pa $q$ entendais y muy particularmente inquirais los ynds q los caciques y otras personas obieren escondido y encubierto a los visitadores q hizieron los padrones y los ynds q dexaron de poner en ellos de 50 as. pa arriva y de 18 pa abaxo q vos entendais os parezca q justam te podrian tributar y pa hazerlo puede travajar como los demás seg el subjeto $q$ vieredes $q$ tienen y me embiareis mema particular dellos.

yten por quanto una de las cosas q mós aficiona a los hombres a sus propias prócticas y naturaleza es el sembrar y crior lo q asimismo los haze ricos y ayuda pa pagar sus trivutos sin pesadumbre y en ningún género de gente conviene tanto tener cuidado como en los naturales de estos reỵnos porq con la opresión y tirania de los yngas que los tenian sujetos y de sus caciques no tenian tacultad pa proveer cosa propia particular y con esto estan descuidados pareciéndoles q estan debaxo de las dhas opresiones $y$ tirania y si no se pudiese remedio en ello enseñándoles y crituandoles a labrar y criar y a ser ricos ni gozarian de la libertad q S.M. a pretendido y pretende ni se conseguiria el fruto del aumentoy conservación de estos reynos y señorios porq faitando la posibilidad a los naturales todo quedaria sin fuerza y seria gente inútil,por tanto hordeno y mando $q$ seg la calidad de la tierra y avilidad de la gente del distrito clonde los dhos corregides residen compelan a los dhos naturales a $q$ siembren y beneficien lo $q$ asi sembraren conforme a la posobilidad de cada uno y tierras $q$ se les dexan aplicadas en comunidad como en particular poniendo pena corporal pa ello y executando las en personasi hallare aver descuido y procurando con ellos q crien algun ganado de Castilla y de la tierra conforme a su calidad y posibilidad y $\mathrm{q}$ no le dexen perder, visitóndolo el dho corregr cada año una vez pa ver el recaudo q en eilo tienen usando en esto oficio de xrano $y$ celoso de la conservación de lo q tiene a cargo y poniendoles alguna pena liviana como no sea pecuniaria $y$ amenczándoles $q$ si no le hizieren, porq este es el medio $q$ se ha de efectuar $y$ poner persona $q$ lo saque todo a pastar fuera de el dho pueblo si fueren ovejas o puercos q es lo q puede andar cerca y le paguen su trabajo al uso de España y q crien gallinas y Ias demas cosas q llevare cada repartimto. en la prov. de vro distrito.

Yten no civeis de consentir $q$. los ynds. de vro distrito anden en cava llos ni en yeguas con sillas y frenos si no fuere con expresa licencia mia so pena $q$ el cacique o indio que andubiere con la dha silla y freno en los dhos caballos o yeguas,los tenga perdidos y los aplicareis el valor dellos por tercuas paries cámara,juez y ospital io qual hareis cumplir y executar sinembargo de cualquiera otra cosa q este proveida en contrario por las ordenanzasq tengo dadas porq esto pareze $q$ conviene prohibilles solamente y no $q$ no tengan los dhos cavallos y yeqguas pa su servicio y cargas $y$ aprovecharse dellos como anden sin sillas y frenos. 
Yten os informareis qué mestizos biven entre los inds. biviendo mal y dándoles mal exemplo y haziéndoles otros agravios y los $q$ bieredes $q$ los hazen los desterrareis de los dhos repartimientos pa q se recoxan y bivan entre los españoles y pidiendo testimonio del destierro se lo dareis con las causas q pa ello ay.

Iten por quanto el corregr del distrito pa $q$ estais nombrado a quien aveis de tomar residencia a usado el dho oficio en muchos repartimtos $y$ pueblos de inds. q estan distantes unos de otros enclavadosen el dho distri to y si luego como llegasedes a él y tomasedes la vara de corregr publi cásedes la residencia no seria posible $q$ en el término de los 30 días $\mathrm{q}$ conforme a su derecho se os da pa tomarla si el Corregr vro antecesor obie se hecho agravios los podais averiguar y las partes venir a pedir su justicia $\mathrm{y}$ conviene proveer en ello de remedio, por tanto ordeno y mando $\mathrm{q}$ luego como tomáredes la bara del oficio deis aviso a todos los caciques e inds. de las cabeceros y pueblos principales de los repartimientos del dho distrito pa q de alli se de a entencer a los demas de cómo vais a ser su corregr y tomar la dha residencia pa $q$ si tienen $q$ pedir y demandar en ella al dho corregr lo puedan hđzer señalándoles el pueblo adonde aveis de asistir $\alpha$ tomarla $q \alpha$ de ser en el repartimto o pueblo prpal. $q$ estubiere en el más comedio del dho distrito $\mathrm{y}$ el dia $\mathrm{q}$ la aveis de comenzar $\mathrm{q}$ a de ser dentro de 15 dias después de aver recibido la dha vara porq no sea molestado con más dilaciones el dho Corregr a quien aveis de tomar la dha residencia $y$ en los dhos 15 dias podreis vos sinembargo de $q$ aveis de embiar el dhomaviso dar vuelta al dho distrito o a los más pueblos principales $q$ pudiéredes $y$ os fuere posible hazer entender $\alpha$ los dhos ynds. cómo aveis de tomar la dha resida informándoos de lo q os pareciere convenir pa $q$ los dhos inds puedan ser mejor desagraviados y pa ello mandareis parescer inds de la parcialidad $y$ entendimiento principales o hatunrunas de cada pueblo y repartimiento del dho distrito y otras personas legas q os pareciere y obiere pa q digan sus dichos y deposiciones en la dha resida En la cual procurareis lomar por testigos algunos de los sacerdotes clérigos o religiosos de las doctrinas pa q mejor se puedan averiguar los agravios y el dho corregr obiere hecho y cómo ha cumplido executado todas las instruccio nes ordenanzas $y$ tasas $q$ le an dado pa el uso del dho oficio lo $q$ al procurareis de inquirir con mucha diligencia $y$ cuidado tomando de los. susodhos los testigos q más entendieredes $q$ tiene ánimo pa dezir la verdad $\mathrm{y}$ el testigo q dixere $\mathrm{y}$ lo save le preguntareis cómo y de qué manera lo save y lo demás segun y de la manera $q$ se os ordena por la provisión q llevais pa tomar la dha resida so pena de $q$ si la resida $q$ tomaredes $y$ se viere en la Rl. Aud.constare q aveis hecho particular averiguación de lo susodho. por la órden referida seais suspendido del dho oficio de más de las otras penas $q$ conforme a derechomse os devan poner.

Y pa q mejor se entienda la forma q aveis tenido en tomar la dha resida segun dicho es por la RI. Aud. y la razón y causa que tubieredes: en hazer los cargos por las informaciones secretas q tomaredes podréis aI cavo de la dha resida una relación en q deis razón de los dhos cargos y cómo $\mathrm{y}$ de qué manera $\mathrm{y}$ con qué testigos $\mathrm{y}$ por qué preguntas $\mathrm{y}$ con qué 
recaudos y testimonios se obieren se obieren hecho y a qué hojas estan -estareis advertido $q$ aveis de embiar toda la dha residencia y cargos della sin remitir ninguno a la Rl. Aud. si no fuere en los cargos en q conforme a derecho se deviese,executar pena corporal o privación perpetua de oficio $\mathrm{y}$ con la dha resida embiareis razón de las quentas de los bienes de comuni dad de cada repartto del dho distrito y cobranza de tributos y si el dho. co rregr vro antecesor los cobró como se le mandó y si en la distribución dellos se guardó la órden $q$ tengo dada y si lo $q$ se aplica $p a$ las justicias $y$ defensa de los naturales deste reyno conforme a las nuevas tasas está depo sitado en las caxas de comunidad juntamte con las ausencias de los sacer dotes y pesos $q$ se aplican para la fábrica y si de cada cosa destas se a guardado lo $\mathrm{q}$ por $\mathrm{mi}$ está mandado $\mathrm{y}$ a $\mathrm{mi}$ me embiareis testimonio $\mathrm{y}$ relación dello aparte.

Todas las quales quentas aveis de tomar al dho Corregr de lo q fuere a su cargo y a los demás caciques e inds. q ovieren tenido la razón y quenta dello y lo embiareis en partidas distintas de por si juntamte con la dha resida pa q de todo aya claridad $y$ se pueda entender lo $q^{\prime}$ de esto hay $y$ proveerse lo $q$ convenga y en la dha resida guardareis el horden susodho $\mathrm{y}$ todo lo demas $\mathrm{q}$ conforme $a$ derecho $\mathrm{d}$ veis guardar $\mathrm{y}$ os esta hordenado.

$\mathrm{Y}$ porque a quien principalmte tomar la dha quento $\mathrm{Y}$ resida es $\alpha$ los caciques y principales $q$ son los $q$ la espiriencia a mostrado $q$ suelen hazer más agravios a los ynds. a ellos sujetos después de aver concluido con la resida y quenta $q$ tomaredes al dho Corregr $y$ embiado a ladha Rl. Audiencia visitando vro distrito hareis averiguación secreta de cómo biven los dhos caciques y principales y usan sus oficios y si agravian a los dhos inds. $y$ si les llevan más tasa de la $q$ estan obligados a pagar $y$ cobran de los inds. $q$ no la d ven pagar por no obligar la edad o por pasar della y si les echan derramas y otras contribuciones y los alquilan contra su voluntad o les toman sus jornales o les hazen otros agravios pa lo qual tomareis el dicho de algunos de los dhos sacerdotes y de otras personas -españoles e indios q estubieren más sin pasión pa averiguarla verdad y les encargareis el secreto de lo $q$ dixeren $y$ hecha la dha averiguación me la embiareis cerrada $\mathrm{y}$ sellada con secreto $\mathrm{y}$ vro parecer $p a q$ vista por mi yo mande proveer lo $q$ convenga si en la dha averiguacion halladeres $q$ los caciques o principales fueren a cargo a los dhos inds. de cosas $q$ les ayan tomado y llevado $q$ esten líquidas sacareis treslado aparte de lo $q$ esto toca y procedereis contra ellos pa $q$ se restituya a los dhos inds. y lo mesmo en qualquiera tiempo $q$ os,constare $q$ los dhos caciques y principales agraviaren en algo $\alpha$ los dhos inds. en lo susodho o en otra cosa.

\section{La jurisdicción $q$ an de tener los corregidores.}

Porq es justo $q$ tengais toda autoridad $y$ preminencia en vro oficio pa $q$ mejor seais obedecidos y respetados porq asi conviene pa la brevedad y buena expedición de los negocios,hordeno y mando $q$ tengais juridición pa conocer de todos los negocios civiles $y$ crimnales $q$ en vro $d$ strito se 
ofrecieren $y$ ocurrieren asi entre inds. con inds. como entre inds. con españoles o españoles con id. seculares e otras personas de qualquier estado e condición $q$ sean asi a pedimento de parte como de oficio en los casos $q$ oviere lugar e procedereis en los dhos negocios e causas y las determi nareis y sentenciareis como hallaredes $q$ es justicia executando la sentencia - sentencias que dieredes sinembargo de apelación en los casos q de derecho obiere lugar yen los demas $q$ por esta mi instrucción y por la carta acor dada por mi y por la Rl. Aud. de la cd. de los Reyes deveis executar q su tenor de la dha carta acordada, sacada del origl dice asi:

Carta acordada. D. Phelipe, por la gracia de Dios Rey de Castilla \& Dada en los Reyes a 30 dias dei mes de julio de 1568 as. .D. Fco. de Toledo, el. Lic. Paredes, el Lic. Recalde, el Lic. Cepeda,Yo Alvaro Ruiz de Navamuel escrno. de cámara de S.M. la hize escribir por su mandado con a acuerdo del Sr. Presidte y oidores. Registrada. Juan de Murga.chenciller. Lorenzo de Alicrga.

En la cual dha carta ccordada mando a vos los dhos corregidores $y$ a cada uno de vos por lo $q$ os toca $y$ atañe en vros distritos $q$ la guardeis cumplais y executeis como en eila se dice. en los demás,casos y negocios otorgareis las apelaciones en negocios criminales pa el corregr de la cd.de vro distrito e pa ante la Rl. Aud. pa donde las partes apelaren y en negocios civiles de la cantidad que dieredes o los inds.o su protector apelarenlo po dran hazer pa ante el dho corregr o Rl. Aud. qual mas quisieren y apelando los españoles $y$ otras qualesquier personas les otorgareis las apelaciones pa ante sola la Rl. Aud. y no pa ante el Corregr y si lamateria tuere de calidad y entrambas porres apelen entonces entregareis la apelación pa el tribunal pa ante quien el indio obiere apelado $\mathrm{g} p a$ toto lo susodho. $\mathrm{y}$ lo dello dependiente os doy poder y comisión en forme qual de derecho en tal caso se requiere.

iten si ei dho pleito criminal fuere entre un yndio con otro hareis la información, savida la verdad sin hazer proceso ni escrevir cosa alguna sre ello,en lo qual hordeno y mando q podais hazer el castigo hasta dar pena de 100 azotes públicmte. no siendo cacique o personal principal del dho repartimto. $q$ siendo cacique o principal hareis su proceso en forma lo más breve $q$ ser pudiere $y$ en los delitos de menor calidad hareis hazer la satisfacción a la parte $y$ en los unos porneis la determinación con la relación q ovo y y execución della en un libro con dia mes y año firmado de vra mano por la orden $q$ abaxo os será dada en la prosecución destas causas no tendreis el indio, preso arriva de 3 dias so pena de 50 ps aplicados segun costumbre.

$Y$ porq podria ser $q$ el corregr de la dha $\mathrm{cd}$. alcaldes ordinarios o algunos dellos andubieren visitando $y$ en el tpo $q$ estuviere en vro distrito se ofrezcan algunos negocios criminales de españoles con españoles o mes tizos en tal caso ordeno $y$ mando $q$ a dho Corregr y justicia ordinaria le dexeis el conocimiento y determinación dellos aunq vos hayais prevenido en la risión y conocimiento como sea después $q$ el dho corregr o justicia ordinaria oviere entrado ansi en el pueblo donde sucediere el dho delito de vro distrito y siendo el negocio entre ynds. o negros o mulatos conocereis 
vos o la dha justicia ordinaria ,el $q$ primero previniere la causa $y$ en los negocios civiles podeis vos el dho corregr o just. ordinaria conocer y proce deren todos los $q$ ante vos se pidieren durante la dha visita con $q$ asi es tos como criminales de entre inds y españoles y los $q$ previnieren de los dhos inds o negros y mulatos los hayan de determinar y determinen durante el tpo $q$ andubieren en vro distrito $y$ no lo haziendo os lo remitan pa $q$ vos los prosigais $y$ determineis como como si desde el principio los ovierades comenzado $\mathrm{y}$ si fuere de españoles con españoles, civil o criminalmente cono ciendo la just. ordinaria dellos los pueden fenecer en el dho distrito o en ia cd. y q el dho corregr o just. ordinaria no pueda adbocar ni adboquen en si ningun negocio civil ni criminal $q$ ante vos pendiere $y$ subcediere en vro distrito si no $q$ los lo dexe a vos pa $q$ procedais en el como juez $\mathrm{q}$ teneis la la. instancia no siendo de los $\mathrm{q}$ pueden conocer andando visit ando como dho es o en grado de apelación en los casos q se permite y no de otra manera y quando se apelare pa ante la Rl. Aud. el pleito se a de con cluir antes vos mesmo en $2 a$. instancia por muy poderoso conforme a Ia ordenanza de S.M. e no dareis pa las provanzas más de la $1 / 2$ del termino $q$ obiereis dado en la la. instancia y cerrado y sellado le dareis a las partes $q$ apelaren $p a q$ sigan su justa. siendo españoles y siendo inds. le embia reis vos o la entregareis a su protector $q$ lo embie $y$ hareis $y$ concluireis el dho pleito con la mr brevedad y más sumariamte $q$ fuese posible.

$\mathrm{Y}$ por quanto uno de los efectos más principales $q$ a de resultar de la asistencia de jos dhos coregids en todo el reyno es seguir los delincuenies doquiera $q$ ovieren cometido los delitos pa $q$ sean castigados y la república tenga entera satisiacción de lo qual esta agora a avido falta q a sido ocasión principal de determinarse mucha gente bulliciosa $Y$ holgazana no solamte a cometer delitos particulares unos con otros pero generales contra la paz y quietud del reyno tratando motines $y$ alteraciones $y$ quando se a saiido con ellos anque sean desbaratados se an huido del reyno sin per juicio y castigo $\mathrm{y}$ otros $\mathrm{q}$ an sido descubiertos no an podido ser prezos por estar los pueblos de los españoles tan apartados los unos de los otros y por la falta $q$ tiene de propios y hazienda pa seguirlos,hordeno $y$ mando $q$ los dhos correges tengan poder y facultad pa poder seguir los dhos delin cuentes $q$ siendo acusados por sus distritos $y$ asi españoles como inds $y$ todo género de gente de qualquier estado $y$ condición $q$ sean den favor $y$ ayuda pa ello y vayan en su cia. $y$ aviendo tomado el rastro puedan estar por distritos agenos con vara de justa acusando de mano en mano los unos a los otros hasta lo último del reyno pa $q$ en todas partes en aviendo delin cuente tengan aviso pa prenderle y saver el camino q llevó poniendo su nombre cuerpo y señal el $q$ podria ser conocido de manera $q$ como género de hermandad no se puede huir ni dexor de ser castigados lo qual se les encarga $y$ manda a todos en general so pena $q$ si en ello oviere avido negligencia serón privados de oficio en la resida $q$ se les tomare $y$ aviendo hecho lo $\mathrm{q}$ deven premiados $\mathrm{Y}$ gratificados por S.M. $\mathrm{Y}$ por sus visorreyes en su nombre.

$Y$ porq pa el dho efecto ay necesidad $q$ los dhos correges tengan ar mas $y$ cabalgadura bastante hordeno $y$ mando $q$ cada uno dellos sea obli 
gado a tener arcabuz aderezado $\mathrm{y}$ a punto con sus municiones $\mathrm{y}$ buen caballo o mula en $q$ pueda hazer el dho seguimiento $\mathrm{y}$ porq no haya diferen cia cuando se hiziere prisión de los dhos delincuentes y a qual de los dhos correces se deve entregar mando q si obiere cometido el delito en el distrito de algunos dellos vaya remitido de mano en mano preso y a buen recaudo hasta entregárselo y si le oviere cometido fuera de los dhos distritos pongan con el mesmo recaudo cd la más cercana donde fuere preso entregándole al Corregr en la cárcel pública della diziendo la razón y causa de su prisión y me avisen luego dello si fuere el delito $q$ toque en negocios generales $o$ a la Rl. Aud. del distrito donde fuere preso pa q vea lo q sre ello se deve hazer el qual seguimiento an de poner por obra en recibiendo mi aviso de la Rl. A.ud. e del Corregr a los de la dha cd. sin poner en ello impedimento ni excusa so lo dha pena y pa el dho efecto de seguir delincuentes puedan entrar con vara fuera de sus distritos y llegar a donde la necesidad se ofreciere solo o en cia. de los otroscorreges.

$Y$ por quanto conviene q en cada pueblo haya relación de los plei tes $q$ se determinaren $y$ las causas y razones $q$ los jueces tubieron pa la determinación .pa q no tornen los dhos inds. a bolver a los dhos pleitos y tambien pa $q$ al tpo de la resida se vea y entienda lo $q$ se a determina do en tpo de cada uno de los dhos correges hordeno y mando q siendo de los negocios en $q$ ha de executar su senta tenga un libro en cada pueblo en $q$ breve $y$ sumariamte ponga como entre fulano y fulano a pasado pleito e ante el sre tal caso, sre tal delito e q por la provanza de el actor o del reo o por la q tomó de su ofico consto de $l$ gr justa aviendo juntado $4 \circ 6$ testigos de la una parte y otros tantos de la otra en su presencia con $q$ luego de la noticia $q$ tubiere del tal delito verifique la verdad y lo asiente en el dho libro y el dho fulano fue condenado en tal pena y tan cosa 0 absuelto y se executó la sent y en los que hubiere lugar apelación quando viniere la determinación della ponga el juicio senta q dio el corregr o la Rl. Aud. y como se executó de manera q en todos los casos haya claridad y razón $y$ donde no se le manda $y$ advierte particularmte an de provurar los dhos jueces q no haya proceso sino sola la verdad savida conocer de las causas q se ofrecieren como está dho.

$Y$ porq uno de los efectos principales $p a q$ he mandado $y$ proveido $q$ aya correges de naturales es pa q los inds tengan justa corriente por sus causas $q$ les determinen sus pleitos y negocios sin $q$ tengan lugar de acudir $\alpha$ ello a las ciudades ni auds. por los daños q de esto les a resultado $\alpha$ sus personas vidas y haziendas y pa $\mathrm{q}$ los dhos correges les puedan adminis trar la dha justa y acudir a todo lo demás q pa su buen govierno convi niere tengo dado $\alpha$ los dhos inds ordenanzas y nuevas tasas e $\alpha$ vos e $\alpha$ los demás correges esta mi instrucción pa $\mathrm{q}$ conforme a lo q por ella se os comete $\mathrm{y}$ manda mantengais a los dhos inds. en paz y en justa $\mathrm{y}$ ex cuteis lo $\mathrm{q}$ pa su policia y conservación tengo ordenado y de más desto tengo nombrados protectores en las ciudades y Rs. Auds. y cerca de mi persona y abogados $q$ asi ante mi como ante las dhas Rs. Auds. y cavildos de ciu dades puedan pedir lo $\mathrm{q}$ al bien de los dhos inds. conviniere sin $q$ ellos salgan de sus tierras pa lo hazer sinembargo desto e visto $q$ muchos inds 
a cuden a esta corte $\alpha$ pedir negocios $q$ ellos $y$ ios demás correges teneis poder y facultad pa se los despachar y proveer por vras comissiones e ins trucciones y conviene proveer en ello de remedio,por tanto ordeno $\mathrm{y}$ mando $q$ luego como ilegaredes a vro distrito hagais publicar y dar a entender $a$ todos los caciques e inds de el $q$. ninguno salga de su reparto. a ningun negocio $q$ se le ofrezca sin $q$ primero parescan ante vos a dar razón de lo $q$ pretenden $y$ siendo negocio de los $q$ vos podeis determinar proveereis en lo $q$ conviniere conforme $\alpha$ vras comisiones y siendo negocio de cacicazgos e otros de los q por elias no se os cometen ni por vro oficio tengais juris dicción asentareis a las espaldas de sus peticiones e pa relación vra firmada de vro nombre de cómo vos no teneis poder pa proveerlo $q$ ansi os piden y embiareis las dhas peticiones e relación o al protector de la cd de vro distrito pa si el corregr della tubiere facultad pa lo poder proveer lo pida ante el y si no la tubiere lo embiareis ai protector de la Aud. o al general q reside cerca de mi persona pa q pida lo a en la dha petición se contu biere conforme al caso y manera $q$ fuere, enviando las tales peticiones $y$ relaciones con personas ciertas excusando en quanto fuere posible $y$ no vengan inds a ello con apercivimiento $q$ si de otra manera parecieren en esta corte o ante las dhas Rs. Auds. o justicias de las ciudades no serán oidos ni despachados sino se mandarán castigar y vueltos los castigareis allá en lo qual aveis de poner mucho cuidadoy diligencia y responder a los dhos inds. a lo $q$ ante vos pidieren so pena de $100 \mathrm{ps}$. la mitad pa la cómara de S.M. Y la otra mitad pa el denunciador e ospital de los inds. de vro distrito por cada vez $q$ en lo susodho incurriédes $\mathrm{Y} q$ en la resida se os execute esta pena por el $q$ os la fuere a tomar $y$ haga particular averiguación sre ello $y$ se permite a los dhos inds a quien no proveyeredes a sus demandas conforme $\alpha$ io $q$ está dho.q puede ocurrir a quejarse al corregr de la cd. de vro distrito por mano de su protector pa $q$ baga la averiguación de cómo no respondisteis a las demandas de los dhos inds. y me embien relación dello a mi o a las Rs. A.uds. pa $q$ se execute en vos la dha pena y si el caso fuere tal q lo requiere se proveera por mi cómo secis suspendidos del dho oficio $y$ no proveido más en otro $Y$ el protector de la dha cd tendrá muy particular cuidado de avisarme de lo $q$ en elio pasay cómo se cumple y guarda y en las cosas q yo o la Rl. Aud. oviere mos de proveer por no os estar cometidas me embiareis siempre vro parecer bien advertido pa $q$ con ese provea lo q más convenga.

y asimismo por quanto esta por mi proveido en las ordenanzas de los inds. $q$ en cada un año se provean alcaldes ordinarios de inds $q$ asisian con sus baras en los dhos pueblos y es razón q tengan alguna jurisdicción los correges ternan especial cuidado q las elecciones se hagan como se contiene en las dhas ordenanzas en cada un año con tanto q no obstante $q$ por las dhas ordenanzas está mandado $q$ los dhos alcaldes sean del pueblo más cercano,porq a parecido $\mathrm{q}$ esto trae inconveniente respeto de $q$ a los dhos alcaldes no se les da salario ni siendo de otro pueblo teman ni tiene con que se poder sustentar en el pueblo donde asi avian de ir a usar sus oficios ,ordeno y mando $q$ los dhos alcaldes lo proveais $q$ sean naturales del mesmo pueblo ,los más idóneos $y$ suficientes $q$ obiere con $q$ 
no puedan ser ni sean caciques y $q$ los dhos alcaldes asistan cada $3^{\circ}$ dias una hora con sus baras en la puerta de las casas de su cavildo haziendo dar un pregón a un indio por el pueblo q esté diputado pa esto en cada un año pa q los q quisieran pedir justa o obieren recivido algun agravio la vengan a pedir y los dhos alcaldes podrán mandar satisfacer a los dhos inds. y ternan su jurisdicción pa ello asi civil como criminal hasta dar a un ind. os 50 azotes o mandalle pagar algun daño $q$ oviere recibido porq todos son menudos y de poca sustancia ,pero si fueren pleito entre los caciques e principales contra algun cacique o principal o indio particular dexalle an reservado pa el dho corregr porq por algunas consideraciones $q$ a ello me ,ovieron es justo $q$ los dhos alcaldes conozcan de las dhas causas.

$Y$ por quanto conviene $q$ los dhos correges instruyan $y$ enseñen a los dhos inds cómo han de juzgar las dhas causas pa q sepan y entiendan cómo lo an de hazer en s ausencia y ansi mesmo $q$ les den autoridad $p a$ $\mathrm{q}$ todos les tengan respeto,ordeno $\mathrm{y}$ mando $\mathrm{q}$ los dhos correges de naturales el tpo $q$ se hallaren presentes en los dhos pueblos teniendo los dhos alcal des sentados junto a si les mande $q$ en su presencia hagan las averigua ciones de las causas $q$ se trataren $y$ entienda con la lengua lo $q$ tienen crveriguado y les diga a determinen las causas delante de el y en su presen cia y si biere $q$ la determinación es justa les diga aquello es justa y razón y se la dexe executar y si biere $q$ no lo hazen conforme a razón les enseñe lo $q$ nosotros hazemos en semejantes causas de manera $q$ los dhos alcaldes entiendan $q$ se lo dize con todo amor $y$ deseo $q$ acierten $y$ se industrien $\mathrm{y}$ aprendan lo $\mathrm{q}$ deven hazer en sus oficios.

$\mathrm{Y}$ por quanto asi mismo pa la execución de la justa conviene $q$ en cada un año se haga 2 alguaciles ordinarios $y$ executen los mandameintos de los alcaldes y del corregr quando biniere a los dhos pueblos y haga llamamientos $q$ los susodhos se elijan el mismo dia $q$ se eligieren los alcaldes $y$ porq an de andar ocupados ,conviene $q$ vos el dho corregr ten gais cuidado $q$ se les hagan sus chácaras y de alguna pena satisfacerles su trarajo y lo mesmo se ha de hazer $\alpha$ un alcalde de lacarcel $q$ asimes mo se ha de elegir y pa $q$ de aqui adelante los sacerdotes $y$ religs no an de nombrar alguaciles ni dar bara ni tienen necesidad dellos asi pa bus car los enfermos como pa otros efectos tocantes a su dotrina de quien lo ayude,mando $q$ de los mayores muchachos de la dotrina se elijan $2 \circ 3$ a los quales el dho corregr de las baras $y$ les mande $q$ cumplan lo $q$ el dho sacerdote les mandare e que cumplido con lo susodho no se pongan ni elijan más baras por los unos ni por los otros si no fuere en tpo de mu cha necesidad hasta tanto $q$ por $\mathrm{mi}$ por los virreyes o governadores $q$. subcedieren otra cosa se provea y mande.

Iten por quanto pa cumplimiento de los dhos caps. e instrucción q se da $\alpha$ los dhos correges es muy necescria su asistencia en los pueblos $q$ estan $\alpha$ su cargo pa ver $\mathrm{y}$ entender lo $\mathrm{q}$ en ellos se contiene $\mathrm{y}$ hazerios cum piir $\mathrm{y}$ executar $\mathrm{y} q$ los naturales entiendan $q$ se tiene cuidado dellos $p a q$ no excedan de lo $q$ les está mandado, ordeno $y$ mando $q$ los dhos correges de natural no asiston en cada pueblo de los de su distrito más q 15 dias porq los puedan visitar a todos de ordinario si no fuere por causa muy 
urgente e pa q lo susodho sea sin molestia ni vejación de los inds $\mathrm{q}$ de ningun negocio $q$ ante eilos pasare les lleve ningun género de derechos ni comida ni ración ordinaria ni extraord. sino q la q hubieren menester la compren al indio y se la paguen en su propia mano y q por los delitos $\mathrm{q}$ los inds. cometieren no les puedan echar ni echen pena pecuniaria ni les obligue a servicio personal si no fuere las" q estan esta cd. a los caciques q yo dexo nombrados por tales y dados títulos de los dhos cacizagos $y$ estas en los casos q estan expresos en los dhos caps. y lo mismo advertiran $q$ hagan los sacerdotes $y$ jueces eccos. $q$ fueren por el dho distrito porq S.M. los exime de las dhas penas por su necesidad y por los inconvenientes $q$ resultaran de llevárselas $\mathrm{y} q$ las $q$ les obieren llevado retengan y hagan retener del salario $\mathrm{y}$ sínodo $q$ les an de pagar de las caxas de las dhas comunidades otra tanta cantidad q quede pa el común de la dha caxa de comunidad.

$Y$ porq tambien es justo $q$ si los dhos inds. an recivido algunos $\alpha$ gravios $q$ sean notables de los visitadores $y$ sus oficiales $y$ reducidores $q$ an visitado sus distritos se les haga hazer satisfacción dello como co hechos en oro $y$ plata o en ropa o en servicios personales de mitayos o echado derramas pa el dho efecto llevándoles más de lo q por mis instrucces les fue mandado $\mathrm{q}$ diesen sre lo $\mathrm{q}$ si obieren de benir a pleitos serian los gastos excesivos mayormente $q$ teniendo los registros y guardas dellos donde asientan todo lo $q$ dan en sus pueblos e marca mayos $q$ tien quenta $y$ razón con ella seria de mucha costa traellos pa hazer las dhas averigua ciones "mando $\mathrm{q}$ si los dhos inds se agraviaren de algo de lo suso dho. $y$ no de otra manera $q$ los correges de los naturales tomen la información sumaria por los dhos sus quipos y registros juntando las personas a cuyo cargo los naturales lo tienen puesto cerrada $\mathrm{y}$ sellada la informn de lo susodho la embien a buen recaudo a los dhos defensores fiscal $y$ abogado de la Rl. Aud. pa $q$ ellos lo bean y presenten $y$ informen $p a q$ los dhos inds reciban entera satisfacción del agravio $q$ obieren recivido pa lo qual se les da a los dhos correges poder cumplido gual en tal caso se requiere avisando ellos ante todas cosas a los dhos inds. $q$ digan la verdad porq si se entendiere nomaver pasado asi seran castigados con todo rigor y $q$ en todo los demás de las reducciones y proveimientos de los dhos visitadores los dhos Correges no se entremetan en manera alguna como les está mandado sino pa hazer guardar y cumplir $y$ executar lo proveido por los dhos visites $y$ de terminada la dha causa por la dha Rl. Aud. sre los dhos agravios mando $q$ se execute breve $y$ sumariamte inemborgo de qualquiera suplicación $q$ en eilo se interponga ,los quales dhos negocios no se an de embiar a ninguna cd. sino a la Aud. del distrito donde estubieren.

$\mathrm{Y}$ porq se pueden ofrecer algunas causas tocantes $\alpha$ los inds. q resi dieren en las ciudades donde están y residen las Rs. Auds. en tal caso los SS Presidente e Oidores della puedan tomar las causas de los tales ynds. y las vean hallándose pte. el fiscal y su procurador porq con más brevedad y expedición se despachan.

$Y$ porq se a pretendido y pretende como declaro en estas ordenanzas quitar a los inds. todos los gastos $q$ puedan hazer en sus pleitos y peticio 
nes $q$ dan ante mi,ordeno y mando $q$ todos los decretos $q$ por mi se decreta ren en las peticiones de los dhos inds. yendo rubricados de mi rúbrica y refrendados de mi srio. se guarden cumplan y executen ni más ni menos como si de los dhos decretos o qualquiera dellos se diera provisión ,pena $\mathrm{q}$ lo contrario haziendo se cobrará de vos 500 ps. de pena pa la cámera de S.M. más los gastos $q$ de lo contrario se hizieren y recrecieren a los dhos inds. de lo qual se os hará cargo en la dha resida pa se executar la dha pena.

De los procuradores $y$ defensores de los inds. $y$ de la órden $q$ a de aver en determinar sus causas.

Par quanto después de aver visto las resultas de la visila gral.e por vista de ojos en las chancillerias de los Reyes y de la ca de la Plota e informaciones $q$ e tenido particulares asi de las provisiones $q$ hallé en el valie de jauja como de los q tengo relación averse proveido en to to el reyno e procesos $q$ estan en los archivos de los secretarios $y$ escrivanos procurando ver el negocio de raiz por la verificación posible entiendo clara mente $q$ el mayor daño $q$ reciben estos inds. y en lo q S.M. más convieno q provea es en quitarles los pleitos de los quales a resultado las derramas y las muertes de gran suma de inds. yendolos a seguir fuera de sus tempies e tierras en compañia de los dhos caciques e gran disipación de sus hacien das y gran numero de perjuros aviéndose avituado tanto $\alpha$ eilo $q$ de los repartims embian los viejos a las ciudades comarcanas pa solo efeto q sean testigos tomando aquello por trato e granjeria $y$ otras muchas cosas $q$ de la ocasión de los dhos pleitos se siguen perjudiciales pa los dhos naturales $y$ de grande inconveniente pa pa la conversión de sus ánimás y conserva ción de sus haziendas q q a sido uno de los fines q e tenido pa provecrios dhos correges de naturales y hazer otras prevenciones en la resulta de la visita $Y$ pa $q$ lo susodho haya enteramente efeto revoco e anulo e doy por ningún valor y efeto todos los defensores, abogados y procuradores de los dhos inds. $q$ hay en todas las Auds. ciudades $y$ villas deste reyno $y$ por el $q$ les hayan dado pa los dhos pleitos causas $y$ salrios q les obiencun cire cido e a $\mathrm{q}$ se obieren obiigado por la dha razón e q ninguno dellos directa mente ni por tercera persona puede recivir quexa ni demanda de los dhos $\mathrm{ni}$ de ninguno de los caciques principales ni de menores ni las hagan o puedan hazer petición ni alegación por ellos en las auds. ni ante los corregs alcaldes ni jueces ni lleven ni piedan lievar cosa ninguna en plata ni oro ni otros presentes por $q$ hablen y abogen y procuren por ellos so:a mente puedan a los visorreyes y a los Presidentes personalmente dezirles vocalmente si entendieren $q$ algun indio a recivido algun agravio $\mathrm{pa} q$ lo mande ver y q el tal letrado o procurador q se hallare aver hecho lo contra rio de lo en esta ordenanza en todo o parte dello por la la. vez pague 50 ducados de valor de a Il rs. y un maravedí aplicados por tercias pares ć́mara,juez y denunciante y por la $2 \alpha$. de 200 ducados e privación de ofjcjo por 2 as. e qualquier otra persona de qualquier estado y condición q fuere contra lo en esta ordenanza contenido o parte dello levando a los inds 
- qualquiera delios algún interés de lo susodho o servicio personal de qualquiera bienes $q$ tuviere $o$ salario e estipendios paque la dha peira pecuniaria segun dho es por la $1 \alpha$. y $2 \propto$, vez y man do a todas y qualesquier justicias correges cicaldes delas dhas villas $y$ circiades a los correges de naturales executen $y$ hogan guardar y cumplir segun y como en esta ordexanza se contiene so la mesma pena por cada vez $q$ en la residencia $y$ visita se le mandare tomar se hallare aver incurrido ni executados saviéndoio,pues ellos han de ser ante quien an de ocurrir les diferencias de los nchuralesy veran las peticiones y las procurcciones de los dhos inds. Y si los tales inds después de la dha ordenanza llevaren hocho la petición de mano de los susodhos. si fuere cacique o principal sera desterrado un oño de su repartimiento en el qual no le acuatan con cosa alguna de lo $q$ ios inds. son obligados $a$ dalles $Y$ si tuere indio particular le sean dados 100 azotes.

$\checkmark$ porq entiendo $q$ los encomenderos y personas $q$ lianen inds. con sus chácaras e ingenios e los q tienen servicio en sus casas defenderán los dhos inds. y les procuraran su bien permito $q$ los tales,si los inds, resci vieren agraviosde algunas personas puedan parecer en juicio por ellos $y$ procurar $q$ sean saitsfechos ante los Correges o ante otras qualesquier justicias, con tanto $q$ no hagan peticiones por escrito sino dando noticia dello e informando a ios correges e a las personas a cuyo cargo se pondrá la defensa de los naiurales.

$\mathrm{Y}$ puesto caso y pretendiendo lo sobredho. y $q$ cesasen todas las dife renciasenetre los dhos inds. podia aver $\mathrm{y}$ de esta visita gral resulta la $\mathrm{sa}$ lisfacción de los agravios y comutaciones $y$ excessos de tasa $q$ entre ellos $y$ los encomenderos a avido en los tiempos pasados y asimismo el amojo namiento entre las provs $y$ pueblos $q$ era sre lo $q$ principalte pendian los dhos negocios e pleitos e asimismo el escribano de los tambos sre q tenian grandes diferencias $y$ reyertas $y$ juntamte con sto la verificación cuyos sean los cacicazgos y señorios y puesta órden en sómo los encomenderos no tengan entrada ni salida ni trato ni contrato con los dhos naturales sino $q$ los Correges cobren los tributos y tengan cuenta y razón pa acudir a los encomenderos conforme a lo q les perteneciere de su tasa de manera $q$ en lo pasado no tienen necesidad de pleitos pues sin costas ni bexación suya S.M. se los ha averiguado $y$ en lo porvenir estan atajados con las prevenciones sobredhas y con poner los dhos correges de naturales $y$ caps. $e$ instruccs $q$ se les dieron $y$ con otras de importancia y sustanciales pa $q$ cese no embargante lo qual porq noto $q$ los inds. ofreciéndoseles algo queden sus causas indefensas puesto $q$ no se puede prevenir a todo ni evitar los sucesos de lo q podria acaecer y es justo que quitándolas oca siones sobredhas si acaso algo se les ofreciera asi en negocios $q$ toquen $\alpha$ justicia como govierno especialte en casos criminales de calidad sin $q$ ellos entiendan en ello haya quien los ayude y favorezca ordeno y mando $q$ en seguir las dhas causas se tenga la órden sigte.

Primeramte $q$ en las ciudades y provs. donde ay Aud. y está el fiscal de S.M. con obligación de amparar y defender los naturales deste reyno ha ya un defensor $q$ tambien sea procurador de los naturales $y$ un abogado, 
tales personas quales convienen $Y$ por mi seran nombrados. e q quanda aiguno faltare por muerte o ausencia el Presidente de la tal Aud. nombre otro tal en su ausencia entre tanto $q$ por mi será nombrado y proveido, a los quales se dará la órden e instrucciones $q$ en la defensa de los inds. an de tener cada uno en su oficio justamte con las intrucces $q$ se dan a los correges de los dhos naturales y con la órden q S.M. tiene dada e yo en su nombre ordenado una provisión firmada de $\mathrm{mi}$ nombrelos quales dhos abogado,defensor $y$ curador an de tener 2 dias en la semana acuerdo con el fiscal en su casa de todos los negocios q hay de los dhos inds q no sean. los días q S.M. tiene mandado $q$ ia Aud. oiga negocios $y$ pleitos de inds pobres los quales dias an de pedir ellos al Presidte los dexe pa lo susodicho.

$Y$ viniendo el dho pleito a la dha Aud. el letrado defensor veran $q$ viene hecho de parte de los corrges de naturales y considerando $q$ los $q$ estan en su Rl. corona como los demas todos son suyos y estan baxo de su protección $y$ amparo $y$ entenderan bien el proceso y llevarsele an al fiscal de lá Rl. Aud. y sin ayudar más a unos $q$ a otros más de entender la justi cia $\mathrm{q}$ cada uno tiene le pondranen la dha R1. Aud. y como padres de los dhos naturales procuraran dalio a entender al Presidte e Oidores coma la han visto $p a q$ se determine y acave sin formar juicio contradictorio entre las partes y determinándole tornarán a embiar el dho corregr de naturales donde procedió pa q el execute y haga guardar y cumplir lo q por la Rl. Aud. fuere determinado. $Y$ porque los más pleitos $q$ pueden suceder an de ser en tre puebios porq los demás entre inds particulares an de ser menudos y po dria ser $q$ fuesen de diferentes distritos $y$ obiese en ellos diferentes jueces. y tomando la causa cada uno $d$ los susodhos $p a$ favorecer los $q$ estan a su cargo tambien se haze juicio contradictorio $y$ se formarian procesos largos $y$ dificultosos ,ordeno $y$ mando $q$ quando lo tal acaeciere $q$ ambos los dhos jueces oigan la causa y juntos hagan la probanza sumariamte $y$ vean la justa de las partes y si los pudieren concertar q es lo q má conviene lo hagan $y$ si no cerrado $y$ sellado $y$ firmado de ambos a dos y concluso lo embien $a$ el dho defensor $y$ letrado pa $q$ juntamte con el fiscal infor men del hecho verdadero del negocio y lo hagan determinar sin dar lugar a pleitos ni dilaciones porq esto es lo $q$ se pretende e quiere S.M. ,considerado $q$ los pleitos inds son de poca sustancia y calidad y $q$ pierden más en traerlos $q$ no el provecho $q$ resulta con seguir lo $q$ pretenden.

Y si fuere en distrito de las demás ciudades del Reyno donde no está la Rl. Aud. los dhos correges embiaran el proceso en los casos $q$ se deve embiar conforme a los dhos caps. al corregr de la dha cd. en cuyo distrito estubieren en las quales ansimismo y en cada una dellas a de residir un defesor letrado si le obiere pa $q$ reciva los dhos negocios y los comúnique con la justicia $\mathrm{mr}$ dela dha cd. en la forma $q$ está dicho y declarado y si bieren $q$ son claros de condición $q$ se pueden executar embiarán la sentencia $q$ el corregr sre ello diere al dho corregr de naturales $p a q$ ex cuten segun $y$ como fuere pronunciada y si fuere de tanta calidad q. pudiere aver en ella lugar de apelación ante la Aud. le embiarán $a$ dho. letrado defensor $y$ fiscal $q$ en ella residen pa $q$ hagan determinar por Presidte e Oidores sin 
$\mathrm{q}$ indio ninguno ni cacique principal ni a quien tocare tenga necesidad de ir a seguir la dha causa y lo q se determinare en la dha Rl. Aud. lo embiaran a buen recaudo al dho Corregs de naturales pa q lo execute pro curando los unos y los otros $q$ se guarde y haga justicia y satisfagan a las partes y la república en lo q fuere interese sin molestia ni bexación de los naturales porq este es su oficio principal y la razón porqué se señalan $\mathrm{p} \alpha$ el dho efeto encargándoles la conciencia pa $q$ lo hagan $\mathrm{y}$ cumplan $\mathrm{Y}$ descarguen la de S.M. como de su persona se confia.

Y porque podria ser $q$ los casos fuesen tan órduos y de tanta calidad y interese aunq. de esto hay y pueden suceder pocos $q$ en tal caso después de determinados se embie al visorrey el proceso sumario como se ha de hazer en todos $p a q$ el procurador $y$ defensor $q$ asistiere con haga su au diencia en los dias $q$ le estan señalados y él lo bea y haga determinar - embialle al Rl. Consejo de las Indias donde a de aver otro defensor a trate los negocios árduos de todo el Reyno q tocaren en general y particular a los inds. porq con este recaudo alcanzan justicia sin vexación ni molestia suya y no anden perdidos por las Auds. saliendo de sus tierras y temples diferentes donde se an muerto y acavado mucha cantidad por la dha razón.

$E$ porq es justo q el visorrey como amparo prpal de los dhos inds. sepa y entienda cómo se hace el dho negocio y como se cumple y executa lo q S.M. manda y provee pa los efetos contenidos enlo $s$ caps. anteceden tes,ordeno y mando $q$ los dhos correges envien al visorrey o governador una memoria de todos los pleitos $q$ acaescieren en su distrito y los méritos de cada uno sumariamte $\mathrm{y}$ como se determinaron $\mathrm{y}$ executaron las senten cias $q$ en ello se dieren haziendo relación de el cuidado q se tiene en los determinados y remitidos $p a$ pa $q$ la expedición y conclusión dellos sea breve y sumaria,lo qual hagan y cumplan so pena de la tercia parte del salario q obieren de aver año por razón del dho oficio en el qual desde aora les doy por condenados.

Otrosi por quanto S.M. manda q por ser tan conviniente y necesario q aya correges de naturales en las provs. q me pareciese convenir, avién dole parecido muy bien los $q$ se an proveido aveis de entender $q$ de ser executor de lo $q$ yo he dexado acordado y ordenado en la visita gral.de deste Reyno y lo q de aqui adelante se hiziere pa q veais cómo aveis de dar quenta $a \mathrm{mi}$ y a los $\mathrm{q}$ adelante governaren en este reyno de cómo se cumple y executa todo lo $q$ se dexó ordenado y mandado pa q yo y los governadores $q$ adelante fueren la den a S.M. en su Rl. Consejo y asi os mando lo cumplais y executeis porq asi lo quiere y manda S.M. embiandome la quenta de lo q executaredes de 6 en 6 meses.

$Y$ por quanto conviene $q$ lo $q$ está hecho $y$ ordenado $p a$ amparo $y$ defensa de los dhos inds. y pa tan notable beneficio suyo lo sepan y entien dan y se puedan aprovechar dello y $q$ de aqui adelante no tengan necesidad desalir de sus tierras a seguir los pleitos $q$ se les ofrecieren ni hazer los gastos extraordinarios $q$ hasta aqui hazian ,pues tienen defensores nombra dos $q$ entiendan bien en su defensa y en procurar $q$ se les guarde su justicia 
a los quales no an de acudir con salarios ni otros servicios personales ni tienen necesidad dello,ordeno y mando $q$ los correges en todas congrega ciones de los pueblos de su distrito hagan juntar todós los caciques y principales y los demás inds. $q$ pudieren $y$ en las dhas congregaciones por lenguas diestras se les de noticia de lo por mi proveido en todo lo $\mathrm{q}$ toca a su defensa muy especificadamente de manera $q$ lo entiendan y las penas $\mathrm{q}$ se ponen al q lo contrario hiziere porq no tengan de pretender ignorancia y quando hizieren memoria sumaria de los dhos pueblos me embien fe de cómo se ha hecho esto. asimismo mando porq venga a noticia de todos los demas los dhso correges en cada cd y villa destos reynos hagan pregonar públicamente en lengua española y de inds, y pongan testimonio del dho pregón en el fin de las ordenanzas q a de sacar el escrivano del cavildo y quedar en su poder las demás q hay hechas pa el buen govierno de la república lo qual hagan y cumplan los correges luego q biniere a su noticia so pena de 500 ps. aplicados por tercias partes cómara,juez y denunciante.

En todo lo qual vos el dho corregs tendreis con la diligencia y cui dado $q$ de vos se confia como negocio $q$ tanto importa al servicio de Dios N.S. y de S.M. y bien y conservación de los naturales guardando y cum pliendo y haziendo guardar y cumplir en lo $\mathrm{q}$ a vos toca en vro distrito $\mathrm{y}$ jurisdicción lo contenido en la dha instrucción y capitulo della segun y de la manera en ellos y en cada uno dellos contenido y sin exceder dellos en cosa alguna haziéndolos publicar en cada un año como en esta instrucción y ordenanzas se manda pa $q$ venga a noticia de todos $y$ ninguno pueda pretender ignorancia y no dexeis de lo ansi cumplir so las dhas penas y q de todo se os tomará particular quenta en la residencia q diere des de el oficio y por la pte. mando al corregr q os la tomare q por los dhos caps. baya averiguando si los aveis cumplido i os haga cargo de lo $q$ o vieredes dexado de cumplir y execute en vos las dhas penas y más de 500 ps. de oro pa la cámara de S.M. so pena q en la residencia q se le tomase se verá si cumplió lo susodho y no lo haziendo será condenado $y$ executado en las dhas penas. fha en los Reyes en 30 dias del mes de mayo de mill e quinientos y ochenta años. - D. Fco. de Toledo. - Por mandado de $\mathrm{Su}$ Exca. Alvaro Ruiz de Navamuel. (origl.) 